\title{
Metformin promotes tau aggregation and exacerbates abnormal behavior in a mouse model of tauopathy
}

Erica Barini ${ }^{1 \dagger}$, Odetta Antico ${ }^{1 \dagger}$, Yingjun Zhao ${ }^{2,3}$, Francesco Asta ${ }^{1}$, Valter Tucci ${ }^{1}$, Tiziano Catelani ${ }^{4}$, Roberto Marotta ${ }^{4}$, Huaxi $\mathrm{Xu}^{2,3}$ and Laura Gasparini, ${ }^{1,5^{*}}$ (D)

\begin{abstract}
Background: Alzheimer disease (AD) and other tauopathies develop cerebral intracellular inclusions of hyperphosphorylated tau. Epidemiological and experimental evidence suggests a clear link between type 2 diabetes mellitus and AD. In AD animal models, tau pathology is exacerbated by metabolic comorbidities, such as insulin resistance and diabetes. Within this context, anitidiabetic drugs, including the widely-prescribed insulin-sensitizing drug metformin, are currently being investigated for AD therapy. However, their efficacy for tauopathy in vivo has not been tested.
\end{abstract}

Results: Here, we report that in the P301S mutant human tau (P301S) transgenic mouse model of tauopathy, chronic administration of metformin exerts paradoxical effects on tau pathology. Despite reducing tau phosphorylation in the cortex and hippocampus via AMPK/mTOR and PP2A, metformin increases insoluble tau species (including tau oligomers) and the number of inclusions with $\beta$-sheet aggregates in the brain of P301S mice. In addition, metformin exacerbates hindlimb atrophy, increases P301S hyperactive behavior, induces tau cleavage by caspase 3 and disrupts synaptic structures.

Conclusions: These findings indicate that metformin pro-aggregation effects mitigate the potential benefits arising from its dephosphorylating action, possibly leading to an overall increase of the risk of tauopathy in elderly diabetic patients.

Keywords: Alzheimer disease, Tau oligomers, Caspase 3, Cleaved-tau, Tau phosphorylation, Tau inclusions

\section{Background}

Intraneuronal inclusions made of filaments of hyperphosphorylated microtubule-associated tau protein are neuropathological hallmarks of a subset of neurodegenerative diseases termed tauopathies, a class that includes Alzheimer Disease (AD), corticobasal degeneration, progressive parasupranuclear palsy and frontotemporal dementia. In $\mathrm{AD}$, tau inclusions co-exist with extracellular plaques of beta-amyloid $(A \beta)$, another pathological hallmark of the disease. The levels of $A \beta$ peptides and

\footnotetext{
* Correspondence: laura.gasparini@iit.it

${ }^{\dagger}$ Equal contributors

'Department of Neuroscience and Brain Technologies, Istituto Italiano di Tecnologia, Via Morego 30, Genoa, Italy

${ }^{5}$ Present Address: AbbVie Deutschland GmbH \&Co. KG, Knollstr., 67061

Ludwigshafen, Germany

Full list of author information is available at the end of the article
}

tau species, including total tau and phospho-tau, are altered in the cerebrospinal fluid (CSF) of subjects at risk for $\mathrm{AD}$ several years before putative onset of clinical symptoms [1]. However, only the severity of tauopathy strongly correlates with cognitive impairment in patients [2].

The progression of cerebral tau pathology appears to be influenced by several risk factors and comorbidities, including diabetes and insulin resistance. Patients with type-2 diabetes mellitus (T2DM) develop cognitive impairment and have an increased risk of developing AD (reviewed in refs. [3, 4]). Impaired cerebral glucose metabolism is also detected at early stages in $\mathrm{AD}$ [5] and insulin resistance occurs in the brain of some patients with AD independently of diabetes [6]. Further, molecular markers of insulin resistance co-localize with tau inclusions in AD brain [7], suggesting that impaired 
insulin signaling may be a key factor in the AD pathophysiological cascade. Considerable experimental and clinical data support this view: insulin signaling and insulin resistance affect the physiopathology of tau. Specifically, insulin transiently regulates tau phosphorylation in cultured neurons $[8,9]$, while reduced insulin signaling increases tau phosphorylation both in cultured neuronal cells [10] and in vivo models of insulin resistance and T2DM [4].

Within this context, the use of antidiabetic drugs has been proposed as potential therapy for AD [11]. Among these drugs, metformin is widely used for the treatment of T2DM, due to its safety profile and low cost. Albeit still controversial, there is experimental evidence that metformin may have beneficial effects on cognition. In rats fed with high-fat diet, metformin significantly attenuated insulin resistance and reverts the cognitive impairment induced by metabolic dysfunction [12]. However, other groups reported that metformin has no effect on specific cognitive tasks, such as behavioral flexibility, performance in the Barnes maze or fear conditioning in rodents with insulin resistance $[13,14]$. Still, metformin improves cognitive function in experimental models unrelated to metabolic dysfunction such as the pentylentetrazole-induced kindling [15] and the haloperidol-induced catalepsy in adult mice [16], suggesting that some of its actions may be unrelated to its insulin-sensitizing properties. When applied for a few hours to neurons in vitro, metformin induces tau dephosphorylation either in basal condition [17] or after inducing insulin resistance [10]. However, in the $\mathrm{db} / \mathrm{db}$ mouse model of insulin resistance, metformin dephosphorylates endogenous murine tau without affecting glycemia and metabolic parameters, suggesting that the effects on tau may be independent from the drug's insulin-sensitizing action [14]. Nevertheless, it remains unknown whether in the absence of insulin resistance or diabetes, chronic treatment with metformin ameliorates tau pathology and behavioral performance in a transgenic model of neurodegenerative tauopathy in vivo.

To investigate this central question, we chronically administered metformin to the P301S mutant human tau transgenic (P301S) mouse, which develops tau inclusions throughout the central nervous system, neuronal loss $[18,19]$ and behavioral deficits [20]. Chronic metformin treatment reduces tau phosphorylation in the cortex and hippocampus of P301S mice by inducing protein phosphatase 2A (PP2A) expression via the AMPK/ mTOR pathway. Paradoxically, metformin promotes the aggregation of recombinant tau in vitro and when given chronically to P301S mice, increases both the cortical amount of insoluble tau species (including tau oligomers) and the number of inclusions with $\beta$-sheet secondary structure. This dual action of metformin on tau pathology exacerbates neurodegeneration-induced hindlimb atrophy and hyperactive behavior in P301S mice. Metformin also activates caspase 3, increases tau cleavage by caspase 3 and disrupts synaptic structures. This work suggests that in subjects at risk for $A D$ and tauopathy, metformin's pro-aggregation effects may mitigate its beneficial actions on tau phosphorylation: caution is thus warranted for metformin application in chronic therapies in elderly diabetic patients.

\section{Results \\ P301S mice show neither peripheral nor brain insulin resistance}

We first investigated whether brain tauopathy is associated with peripheral or central insulin resistance. We examined peripheral glucose homeostasis using the intraperitoneal glucose tolerance test (IPGTT) and insulin tolerance test (ITT). For IPGTT, after fasting, mice were challenged with a glucose bolus and glycemia was monitored over $2 \mathrm{~h}$. In both P301S transgenic and wild type (WT) non-transgenic mice, glycemia peaked within 15 min from the challenge, reached similar levels at all time points, and returned to baseline after $2 \mathrm{~h}$ (Fig. 1a), displaying a similar AUC for both transgenic and nontransgenic mice (Fig. 1b). In the ITT, in WT, glycemia quickly declined from the baseline of $134.2 \pm 11.2 \mathrm{mg} / \mathrm{dl}$ to $80.0 \pm 6.0 \mathrm{mg} / \mathrm{dl} 15 \mathrm{~min}$ after insulin injection and started recovering $60 \mathrm{~min}$ later, reaching values comparable to baseline after $2 \mathrm{~h}$. In P301S and WT mice, glycemic values and AUC were similar (Fig. 1c, d).

To test brain insulin resistance, we measured cortical levels of glucose and insulin and analyzed the expression and activation of the insulin receptor (IR) and its downstream signaling molecules IR scaffold-1 (IRS1), protein kinase $\mathrm{B}$ (AKT) and mammalian target of rapamycin (mTOR). In the cortex of adult P301S and WT mice, levels of both glucose and insulin were similar (Fig. 1e, f). To assess IR expression, we evaluated its primary translation product IR $\beta$ at the mRNA level, and its protein precursor (IR precursor) and $\beta$ subunit (IR $\beta$ ). Levels of IR $\beta$ mRNA (Additional file 1: Figure S1A), IR precursor (Additional file 1: Figure S1B, C), and IR $\beta$ protein (Fig. 1g, h) were similar in P301S and age-matched WT mice. Cortical levels of both IRS1 and its form phosphorylated on Serine 616 (p[S616]IRS1), which indicates insulin resistance [6], were also similar in P301S and WT mice (Additional file 1: Figure S1B, D-E). Levels of AKT and mTOR and their active forms phosphorylated on Serine 473 (p[S473]AKT) and Serine 2448 (p[S2448]mTOR), respectively, were unchanged in P301S mice cortex (Fig. 1g, h; Additional file 1: Figure S1F-G). Signaling was similarly unchanged in the hippocampus. In both genotypes, there were comparable levels 


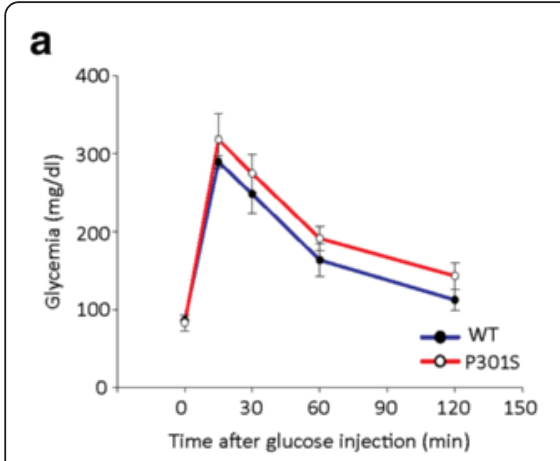

e

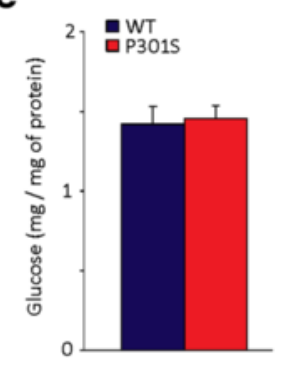

b

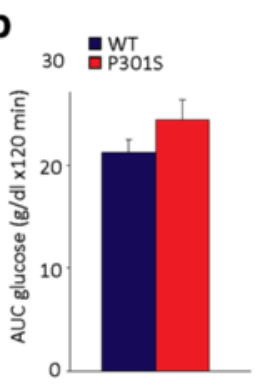

f

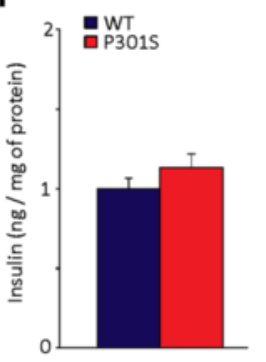

g
C

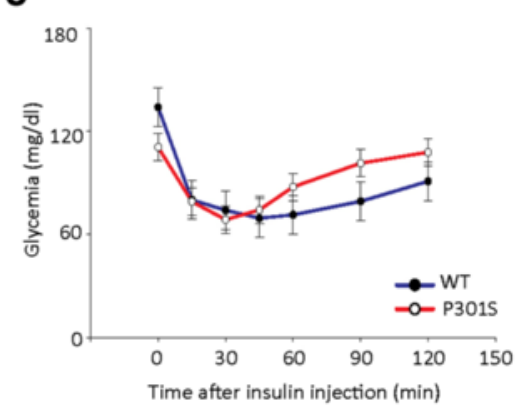

h

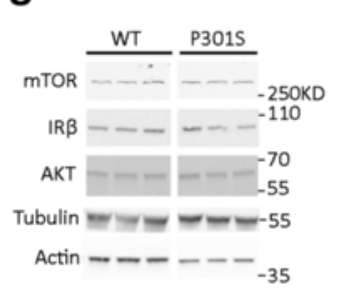

d

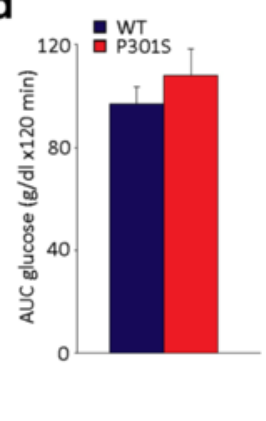

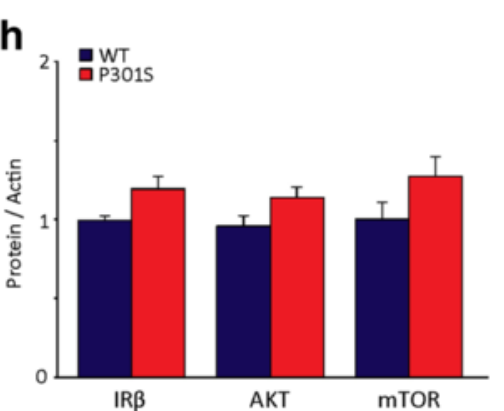

Fig. 1 P301S mice show neither peripheral nor brain insulin resistance. a Intraperitoneal glucose tolerance test (IPGTT) in 5 month old WT nontransgenic and P301S transgenic mice. At time $0, P=0.9 ; 15 \mathrm{~min}, P=0.29 ; 30 \mathrm{~min}, P=0.33 ; 60 \mathrm{~min}, P=0.3 ; 120 \mathrm{~min}, P=0.26$; two-way ANOVA followed by Holm-Sidak multiple comparison test. P301S, $n=10$; WT, $n=12$. b IPGTT AUC. $P=0.17$; Student $t$-test. $\mathbf{c}$ Insulin tolerance test (ITT) in 5 month old WT non-transgenic and P301S transgenic mice. At time $0, P=0.09 ; 15 \mathrm{~min}, P=0.95,30 \mathrm{~min}, P=0.69 ; 45 \mathrm{~min}, P=0.73 ; 60 \mathrm{~min}, P=0.24$; $90 \mathrm{~min}, P=0.11 ; 120 \mathrm{~min}, P=0.22$; two-way ANOVA followed by Holm-Sidak multiple comparison test. P301S, $n=12 ; \mathrm{WT}, n=6$. In a and $\mathrm{c}$, data points represent the average glycemia \pm SEM. $\mathbf{d}$ ITT AUC. $P=0.50$, Student $t$-test. e-f Glucose concentration (e) and insulin levels (f) in the cortex of 5-month old P301S and WT mice. $n=6$ / group. Glucose and insulin concentrations were normalized to the sample protein content. Bars represent the average \pm SEM. In panel e, $P=0.79$; panel $\mathrm{f}, P=0.24$; Student $t$-test. $\mathbf{g}$ Western blot of $\mathrm{mTOR}$, IR $\beta$ and Akt and total tau in the cortex. Actin and Tubulin were analyzed as a loading control. $\mathbf{h}$ Quantitative analysis of protein expression of IR $\beta$ (WT, $n=9 ;$ P301S, $n=12$ ), AKT $(\mathrm{WT}, n=8 ; \mathrm{P} 301 \mathrm{~S}, n=12)$ and mTOR (WT, $n=6 ; \mathrm{P} 301 \mathrm{~S}, n=7)$ in the cortex of 5-month old P301S and WT mice. Protein levels were normalized to actin. Data are expressed as percentage of WT. Bars represent the average \pm SEM. IR $\beta, P=0.06$; AKT, $P=0.09$; $m$ TOR, $P=0.14$; Student $t$-test

of hippocampal IR $\beta$ (IR / actin: WT, $1.0 \pm 0.2$; P301S, $1.5 \pm 0.2 ; \quad P=0.15 ;$ Student $t$-test), IR precursor (IR precursor / actin: WT, $1.0 \pm 0.1$; P301S, $0.8 \pm 0.1 ; P=0.1$, Student $t$-test), AKT (AKT / tubulin: WT, $1.0 \pm 0.2$; P301, $1.4 \pm 0.2 ; P=0.2$, Student $t$-test), $\mathrm{p}[\mathrm{S} 473] \mathrm{AKT}$ (p[S473]AKT / AKT: WT, $1.0 \pm 0.1 ;$ P301S, $0.9 \pm 0.05$; $P=0.4$, Student $t$-test), and mTOR (mTOR / tubulin: WT, $1.0 \pm 0.2$; P301S, $1.1 \pm 0.2 ; P=0.15$; Student $t$-test).

Overall, these results indicate that in P301S mice, neither peripheral nor central insulin resistance associate with brain tauopathy.

\section{Metformin reduces tau phosphorylation in the brain of P301S mice}

To investigate how metformin modulates tau pathology in vivo, we treated P301S mice with or without metformin for 4 months and analyzed levels of tau and its phosphorylation state in the cortex and hippocampus. Currently, metformin is prescribed for T2DM. Considering that diabetes diagnosis and treatment usually precede $\mathrm{AD}$ onset, we administered metformin according to a prevention scheme, starting the treatment at 4 weeks of age, when tauopathy is still minimal and asymptomatic in the P301S mouse [21]. The selected dose $(2 \mathrm{mg} / \mathrm{ml}$ in the drinking water) achieved metformin plasma levels comparable to those obtained by therapeutic dosing in humans (Additional file 1: Table S1) [22] and in P301S transgenic mice, yielded brain levels comparable to those achieved in WT non transgenic mice (Additional file 1: Table S1).

Total tau protein levels were similar in P301S mice with or without metformin, both in the cortex (Tau5 / actin: Ctr, $1.0 \pm 0.17$; Met, $1.03 \pm 0.2$. $P=0.9$, Student $t$-test) and hippocampus (Ctr, $1.0 \pm 0.1$; Met, $1.3 \pm 0.1$; $P=0.15$, Student $t$-test). However, tau phosphorylation was significantly reduced in metformin-treated P301S mice. Levels of tau phosphorylated on Serine 262 and the phospho-epitopes recognized by AT8 antibody were significantly decreased in both the cortex (Fig. 2a-b, d) and hippocampus (Fig. 2c, e). In the cortex of metformintreated P301S mice, phosphorylation on epitopes recognized by PHF1 and AT270 was also decreased (Fig. 2f-g). 


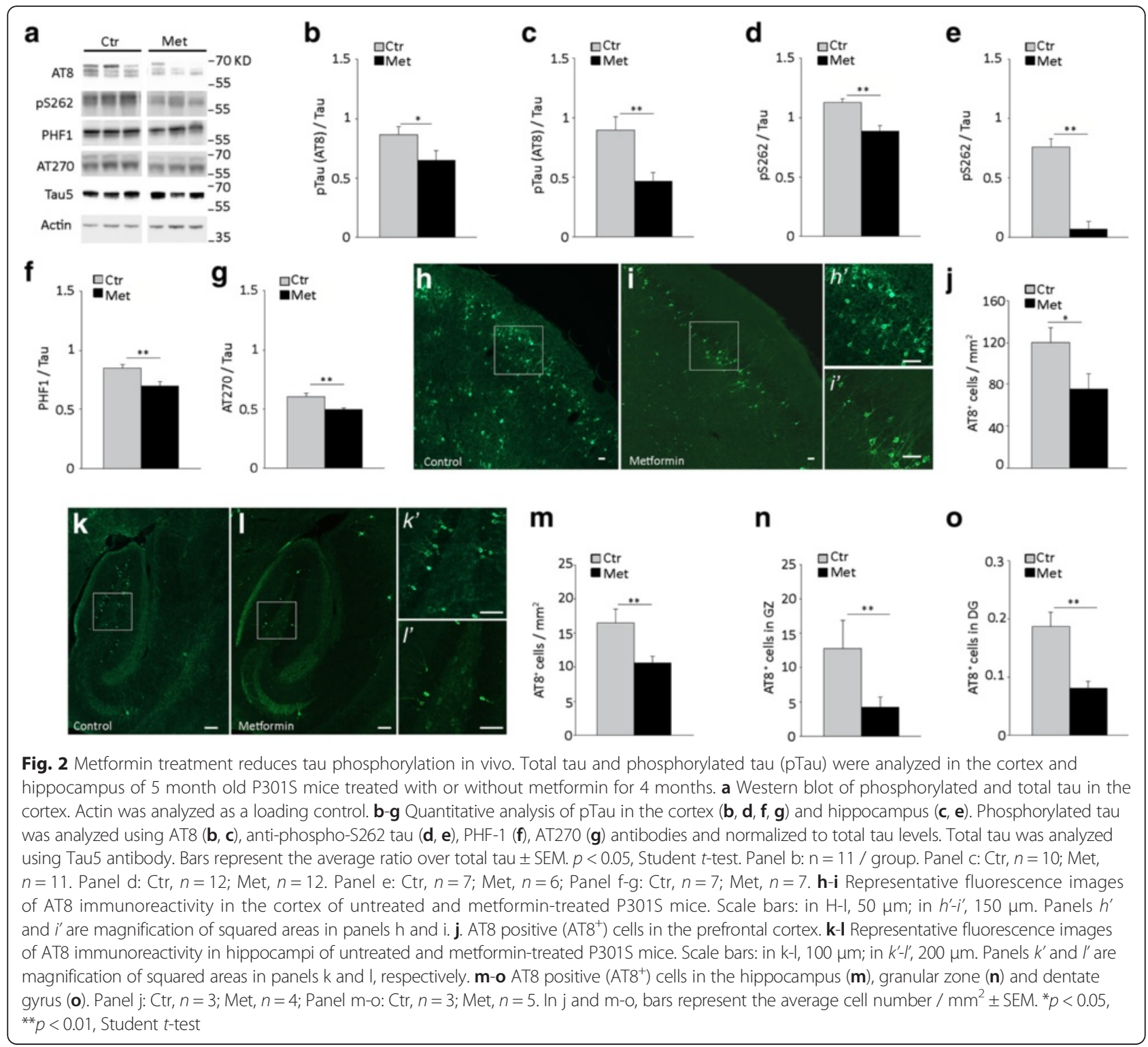

In 5-month old P301S mice, phosphorylated tau accumulates in some, but not all neurons throughout the brain [18], reaching different degrees of tau pathology in distinct brain areas. Consistent with this variation, the number of AT8 positive cells is higher in the prefrontal cortex than the hippocampus of 5-month old P301S mice (Fig. 2h, j, k, m). To investigate whether metformin treatment changes the number of tauopathy-affected neurons, we counted AT8 immunoreactive $\left(\mathrm{AT}^{+}\right)$cells in the hippocampus and prefrontal cortex of transgenic mice treated with or without metformin. Consistent with biochemical findings, in P301S mice treated with metformin, the number of $\mathrm{AT}^{+}{ }^{+}$neurons was significantly reduced in both the prefrontal cortex (Fig. $2 \mathrm{~h}-\mathrm{j}$ ) and hippocampus (Fig. 2k-m). Specifically, in the hippocampus, the number of $\mathrm{AT}^{+}$cells was reduced by $67 \%$ in the granular zone (Fig. 2n), which contains the majority of hippocampal $\mathrm{AT}^{+}$cells, and by $57 \%$ in the dentate gyrus (Fig. 2o), but was unchanged in the subiculum $\left(\mathrm{AT}^{+}\right.$cells $/ 10 \mathrm{~mm}^{2}$ : Ctr, $0.2 \pm 0.03$; Met, $0.1 \pm 0.01 ; P=0.1$, Student $t$-test).

These results indicate that in P301S mice, chronic treatment with metformin decreases the phosphorylation of tau on several epitopes and reduces the number of neurons accumulating phospho-tau in the cortex and hippocampus.

\section{Metformin increases PP2A expression in the brain of P301S mice}

Physiological phosphorylation of tau depends on the balance between protein kinase and phosphatase activity. 
Protein phosphatase 2A (PP2A) is the main tautargeting protein phosphatase [23], while among kinases, glycogen synthase kinase $3 \beta$ (GSK3 $\beta$ ) plays a key role in insulin-regulated tau phosphorylation [24]. Metformin acts on both PP2A [17] and GSK3 $\beta$ [10] in cultured neuronal cells. To investigate how metformin reduces tau phosphorylation in vivo, we analyzed the protein and mRNA expression of PP2A and the protein level and activation of GSK3 $\beta$. After metformin treatment, PP2A protein expression was significantly increased in both cortex and hippocampus of P301S mice (Fig. 3a-c). Specifically, in the cortex, metformin increased PP2A protein expression by $60 \%$ over untreated transgenic mice (Fig. 3b). To test whether metformin acts at the level of transcription, we analyzed PP2A mRNA. In P301S mice, metformin treatment significantly increased PP2A mRNA in both cortex (Ctr: $0.69 \pm 0.09$; Met $1.2 \pm 0.15, P=0.01$, Student $t$-test) and hippocampus (Ctr: $0.96 \pm 0.08$; Met: $1.25 \pm 0.02$; $P=0.01$; Student $t$-test). We next investigated GSK3 $\beta$ and its phosphorylation on Serine 9 (p[S9]GSK3 $\beta$ ), which inhibits GSK3 $\beta$ [25]. Chronic treatment with metformin alters neither GSK3 $\beta$ protein expression nor p[S9]GSK3 $\beta$ levels (Fig. 3d-e), indicating that metformin does not inhibit GSK3 $\beta$ activity.

Overall, these findings indicate that in P301S transgenic mice, chronic treatment with metformin significantly enhances PP2A expression at mRNA and protein levels, without changing overall GSK3 $\beta$ activity.

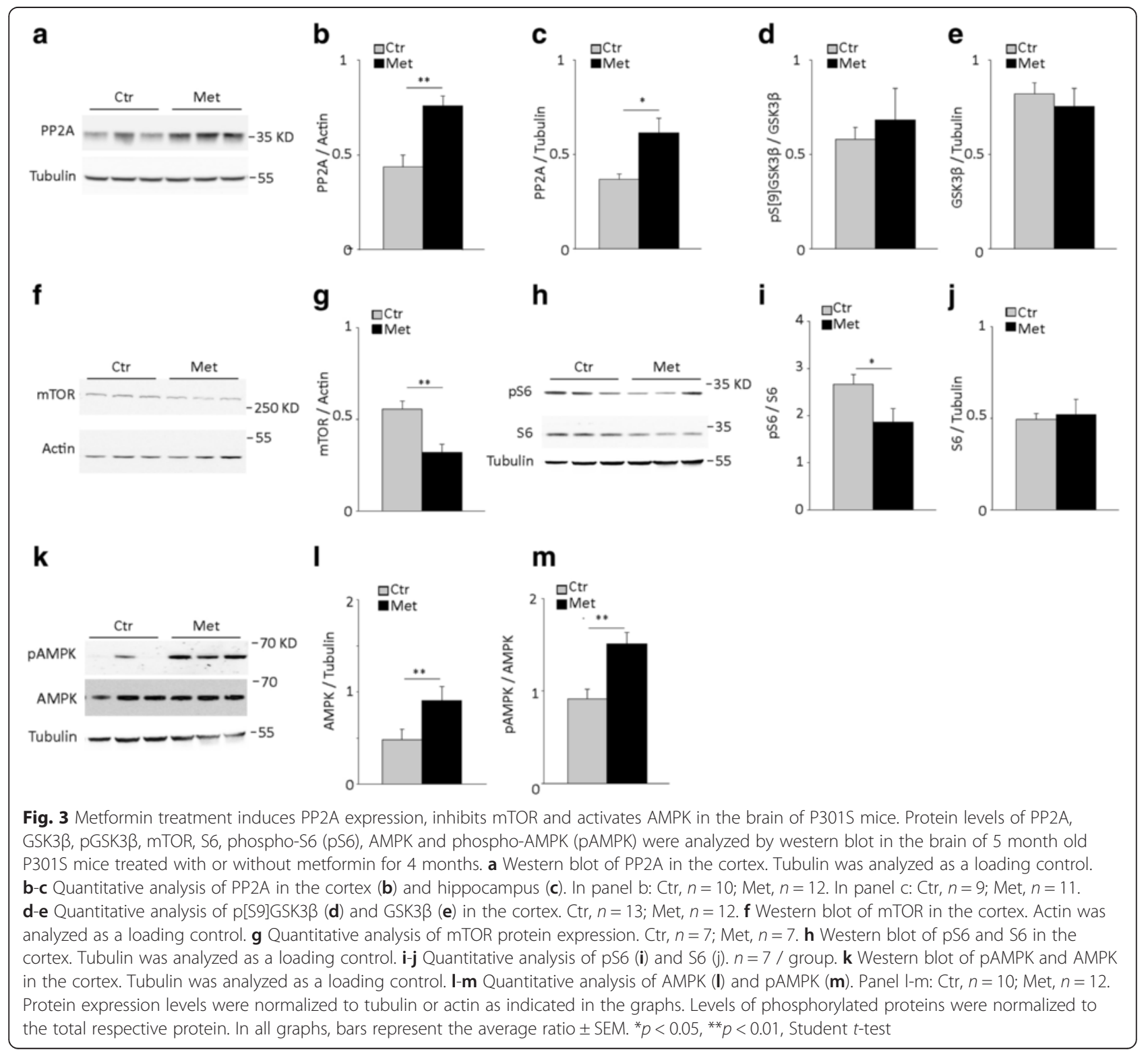




\section{Metformin activates the AMPK-mTOR pathway in the brain of P301S mice}

PP2A is regulated by the integration of several intracellular signals, including the insulin signaling pathway [26] and/or inhibition of mTOR through phosphorylation by AMPK [27, 28]. We therefore investigated whether chronic metformin activates any of these pathways in the brain of P301S mice.

We first analyzed the expression and activation of AMPK and mTOR. Chronic administration of metformin significantly reduced by $43 \%$ mTOR levels in the cortex of P301S mice (Fig. 3f-g). To examine mTOR activity, we analyzed the total levels and phosphorylation of S6 (Fig. 3h-j), the substrate of the mTOR downstream target protein kinase S6 [29]. Treatment with metformin significantly reduced by $23 \%$ the levels of phospho-S6 (Fig. 3i) without affecting S6 expression (Fig. 3j), indicating that metformin inhibits mTOR signaling in the brain of P301S mice.

mTOR is inhibited by AKT phosphorylation on serine 2448 (p[S2448]mTOR) [30] via the insulin signaling pathway and by AMPK phosphorylation on threonine 2446 [31]. To dissect the mechanisms underlying mTOR inhibition, we therefore analyzed the insulin signaling pathway, AMPK and its activation. We first examined levels of $\mathrm{p}[\mathrm{S} 2448] \mathrm{mTOR}, \mathrm{IR} \beta$, IRS1, AKT and its phosphorylated active form ( $\mathrm{pAKT}$ ). There were no significant differences in the levels of these signaling molecules in metformin-treated P301S mice (Additional file 1: Figure S2A-E), arguing against a direct involvement of insulin signaling in metformin's effects on mTOR.

We next investigated AMPK expression levels and phosphorylation on threonine 172 ( $\mathrm{p}$ [T172]AMPK), which indicates its activation state [32]. In P301S mice, chronic treatment with metformin slightly, but significantly increased AMPK protein expression (Fig. 3l) and strongly enhanced its activation (Fig. 3m).

Together, these results suggest that chronic administration of metformin inhibits mTOR and activates AMPK in the brain of P301S mice, without affecting insulin signaling.

\section{Metformin reduces tau phosphorylation through activation of PP2A via AMPK/mTOR in vitro}

Our results indicate that in the brain of P301S mice, metformin increases the expression and activation of AMPK, inhibits mTOR and induces PP2A expression. To investigate whether these signaling and effector molecules mediate the effects of metformin on tau phosphorylation, we incubated primary cortical neurons with or without metformin, alone or in combination with specific inhibitors or activators and analyzed tau phosphorylation. Consistent with previous findings [17], incubation with metformin alone significantly reduced tau phosphorylation (Fig. 4a) without affecting tau expression levels (Additional file 1: Figure S3A). The effects of metformin were independent from insulin. Despite that levels of phospho-tau were significantly higher in neurons cultured in the absence of insulin than in those cultured with insulin, metformin reduced tau phosphorylation similarly in both cases (Fig. 4a).

To examine PP2A involvement, we treated cortical neurons with metformin alone or in combination with the PP2A inhibitor, okadaic acid (OA). As previously reported [17], OA alone increased the levels of tau phosphorylation (Fig. 4b), without changing total tau expression (tau / Tubulin. Ctr: $1.0 \pm 0.08$; Met: $0.97 \pm 0.4$, OA: $0.7 \pm 0.08, \quad$ OA + Met: $0.7 \pm 0.06 . \quad P=0.6$, One Way ANOVA). When co-incubated, OA abolished metformininduced tau dephosphorylation in primary neurons (Fig. 4b) indicating that metformin's effect on tau phosphorylation requires PP2A activity.

We next investigated whether AMPK and mTOR activity were necessary for metformin's action on tau phosphorylation. For AMPK, we incubated cortical neurons with metformin alone or in combination with $10 \mu \mathrm{M}$ dorsomorphin, an inhibitor of AMPK activity in vitro [33]. Dorsomorphin strongly inhibited AMPK as judged by reduced levels of p[T172]AMPK (Fig. 4c) and completely prevented metformin-induced tau dephosphorylation (Fig. 4d), without changing expression levels of AMPK (Additional file 1: Figure S3B). In neurons treated with metformin, mTOR was inhibited in the presence and absence of insulin (Fig. 4e). To examine the role of mTOR in metformin's action on tau phosphorylation, we inhibited its activity with rapamycin, or activated it by overexpressing a constitutive active mutant of the mTOR activator Rheb (S16H-Rheb) [34]. Both metformin and rapamycin reduced tau phosphorylation (Fig. 4f) and inhibited mTOR, as indicated by decreased phospho-S6 levels (Fig. 4g), without affecting S6 protein expression (Additional file 1: Figure S3C). To investigate whether $\mathrm{mTOR}$ is specifically required for metformin-induced tau dephosphorylation, we transduced primary cortical neurons with lentiviral particles containing the GFP reporter along with constitutively active S16H-Rheb. S16H-Rheb activated mTOR in primary cortical neurons as judged by increased levels of phospho-S6 (Additional file 1: Figure S3E, Fig. 4h), leaving unchanged S6 expression (Additional file 1: Figure S3F). S16H-Rheb expression abolished metformin-induced tau dephosphorylation (Fig. 4i), without affecting tau expression levels (Additional file 1: Figure S3G).

Overall, these results indicate that the effects of metformin on tau phosphorylation occur in an insulinindependent manner and require the activity of AMPK and PP2A and inhibition of mTOR. 


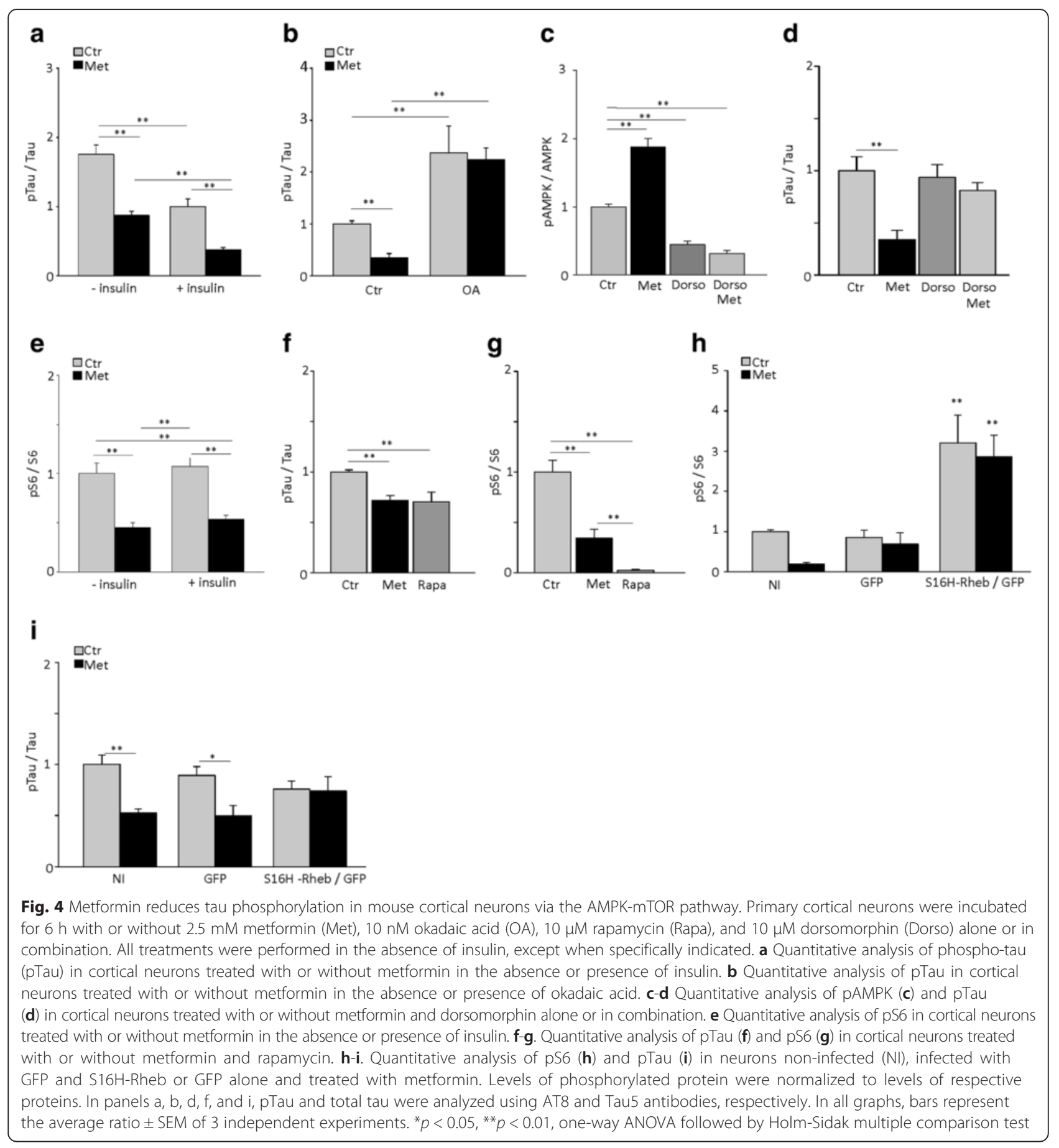

Metformin increases insoluble tau and tau inclusions in the P301S brain and promotes tau oligomeric aggregation in vitro

We next investigated whether reducing tau phosphorylation translates into amelioration of tau filamentous inclusions. We first isolated insoluble tau filaments from the cortex of 5-month old P301S mice treated with or without metformin using the sarkosyl extraction. In the sarkosyl-insoluble fraction of P301S cortex, western blot analysis using Tau 5 antibody revealed major monomeric tau bands at $\approx 58-60 \mathrm{kDa}$, a smear at higher molecular weights with a clear double band at $\approx 115-120 \mathrm{kDa}$, which is consistent with the molecular weight of tau dimers. Bands of monomeric tau were also detected by the AT100 antibody, which recognized conformations typical of tau filamentous inclusions [35]. The amount of insoluble tau, both monomeric and oligomeric, was significantly increased 
a
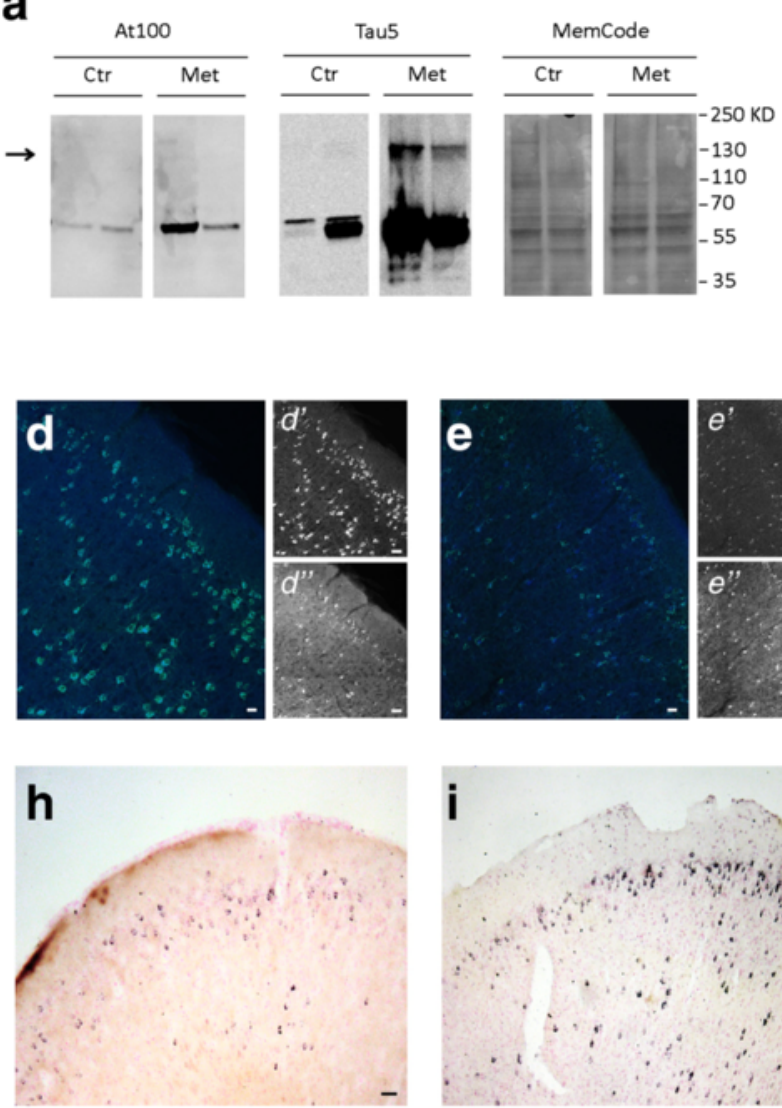

I
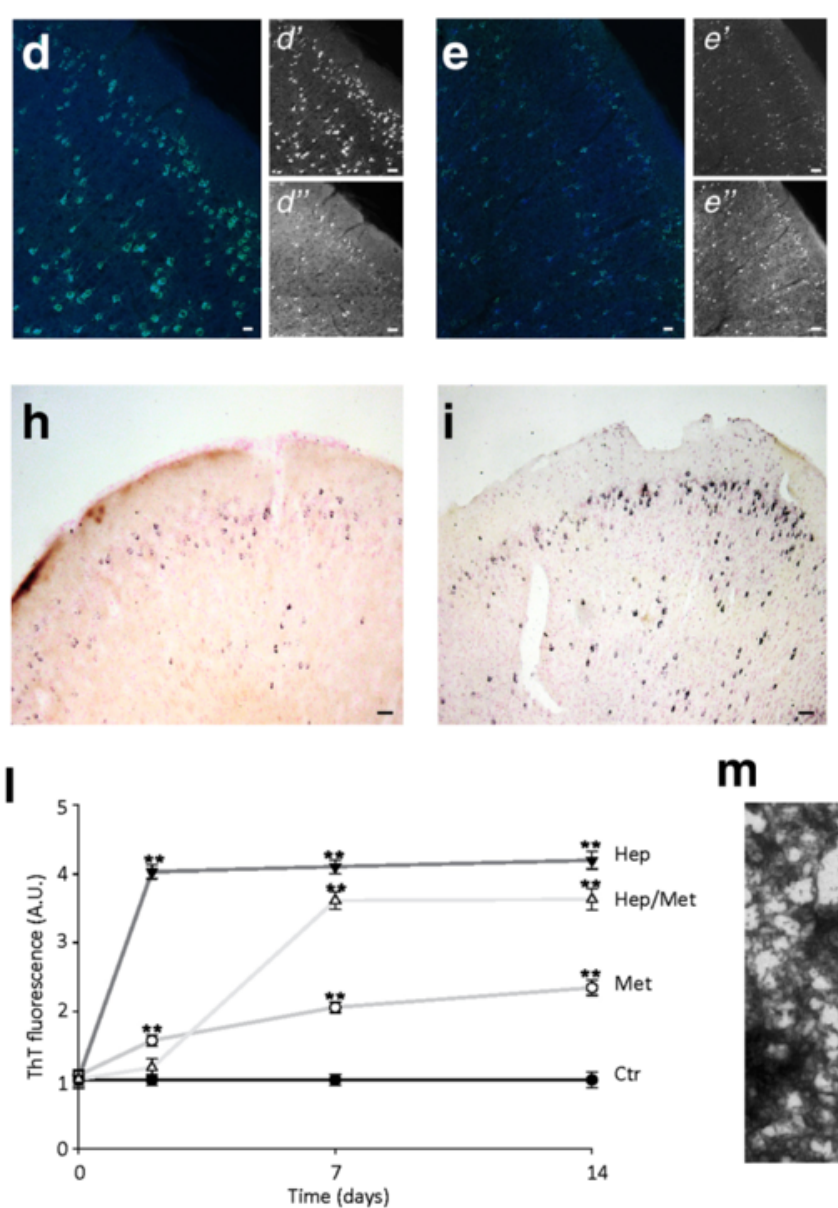

m

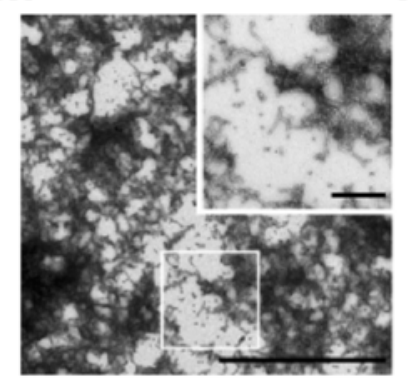

n

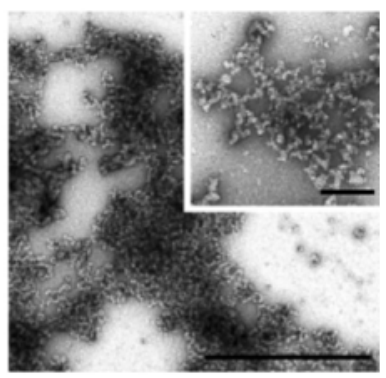

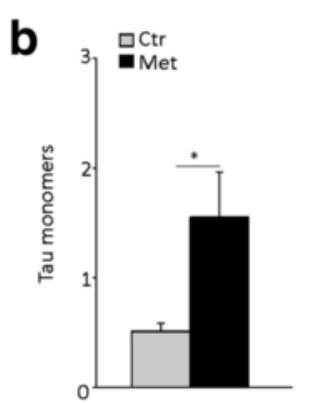
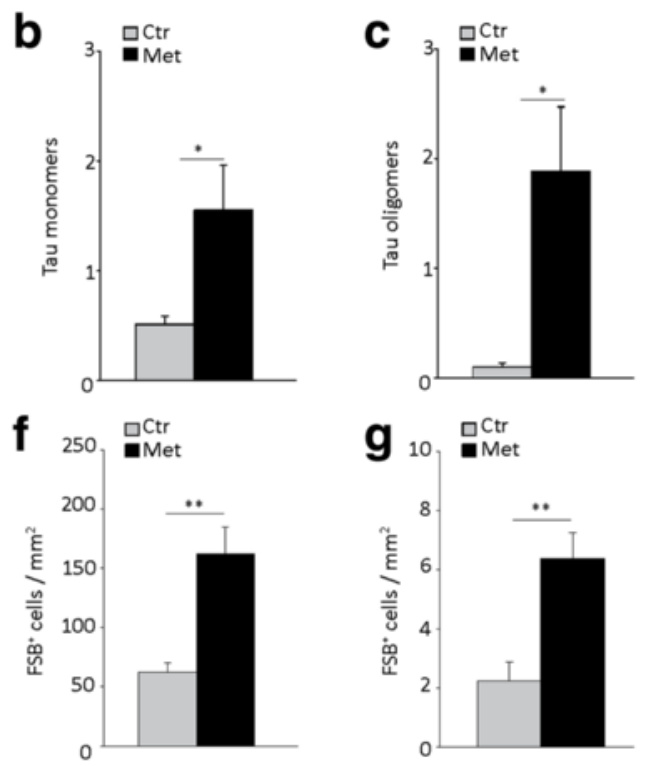

j $400 \stackrel{q_{\text {Met }}^{C t r}}{\mathrm{M}^{2}}$
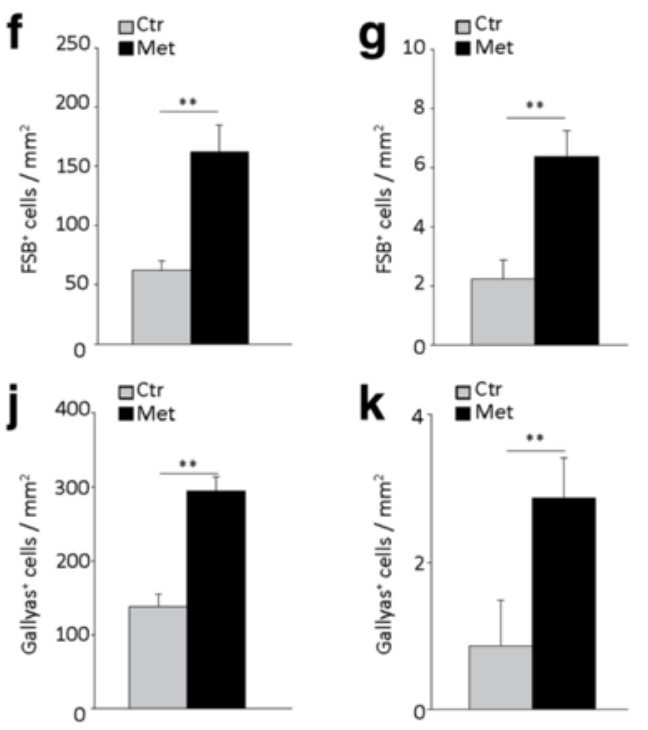

$\mathbf{K}_{4}{ }_{\text {Met }}^{\mathrm{Ctr}}$

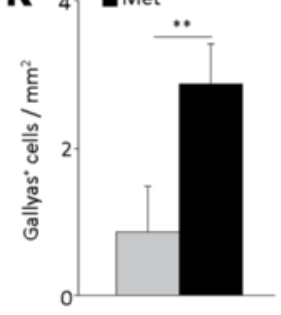

o

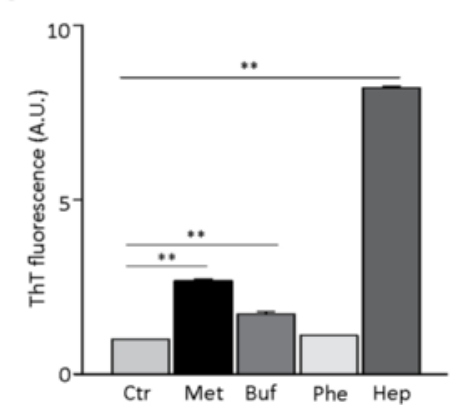

p

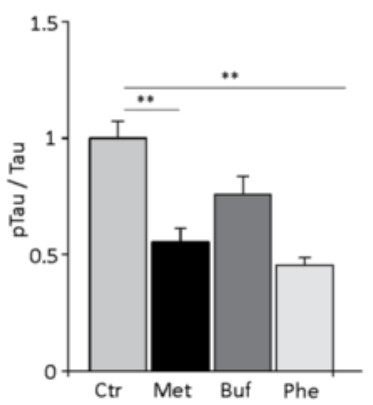

Fig. 5 (See legend on next page.) 


\section{(See figure on previous page.)}

Fig. 5 Metformin increases the number of tau inclusions in P301S mouse brain in vivo and induces aggregation of recombinant P301S tau in vitro. a Western blot analysis of tau in the sarkosyl-insoluble cortical fraction from P301S mice treated with or without metformin. The arrow indicates the bands of tau dimers. Tau was detected using the phosphorylation-and conformation dependent AT100 and Tau5 anti-tau monoclonal antibodies. MemCode was used to control equal loading. b-c Quantitative analysis of monomeric (b) and dimeric (c) tau in sarkosyl-insoluble fractions of P301S cortex. Densitometric values of tau bands are normalized over MemCode and bars represent the average ratio \pm SEM. P301S, $n=4$ / group. $\mathbf{d}$. Representative images of MC1 immunoreactivity (d, d'; green) and FSB (d, d"; light blue) fluorescence in the cortex of P301S mice. Scale bars: in $\mathbf{d}, 50 \mu \mathrm{m}$; in $\mathbf{d}^{\prime}-d^{\prime \prime}, 100 \mu \mathrm{m}$. e Representative images of AT8 immunoreactivity (e, $e^{\prime} ;$ green) and FSB (e, e"; light blue) fluorescence in the cortex of P301S mice. Scale bars: in e, $50 \mu \mathrm{m}$; in $e^{\prime}-e^{\prime \prime}, 150 \mu \mathrm{m}$. $\mathbf{f}-\mathbf{g} \mathrm{FSB}^{+}$cells in the prefrontal cortex (f) and hippocampus (g) of P301S mice. $n=3$ / group. Bars represent the average number of FSB ${ }^{+}$cells $/ \mathrm{mm}^{2} \pm$ SEM. ${ }^{* *} p<0.01$, Student $t$-test.

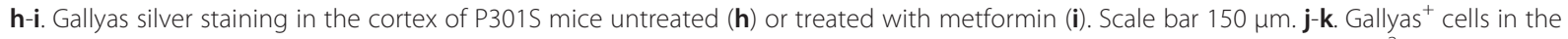

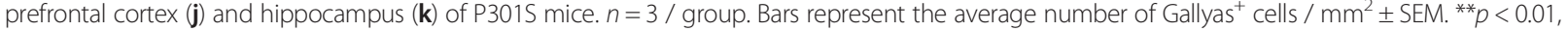
Student t-test. I. Thioflavin T (ThT) fluorescence of recombinant P301S mutant human tau (P301Stau) aggregated in vitro in the absence (Ctr) or presence of $37.5 \mu \mathrm{M}$ heparin (Hep) and/or $30 \mu \mathrm{M}$ metformin (Met) for 2, 7 and 14 days. Data points represent the average \pm SEM from at least 3 independent experiments. $\mathbf{m}-\mathbf{n}$. Representative negative staining electron microscopy image of fibrils of recombinant P301Stau aggregated in vitro for 7 days in presence of heparin $(\mathbf{m})$ or metformin $(\mathbf{n})$. In $\mathbf{m}$, inset shows a high magnification of the squared area. In $\mathbf{n}$, inset shows a high magnification image of tau aggregates. Scale bars: i-j, $2.5 \mu \mathrm{m}$; insets, $0.5 \mu \mathrm{m}$. o ThT fluorescence of recombinant P301Stau aggregated in vitro in the absence (control, Ctr) or presence of $37.5 \mu \mathrm{M}$ heparin, $30 \mu \mathrm{M}$ metformin, $30 \mu \mathrm{M}$ phenformin (Phe) or $30 \mu \mathrm{M}$ buformin (Buf) for 7 days. Fluorescence values are expressed as arbitrary units and normalized to the control. Bars represent the average \pm SEM. ${ }^{* *} p<0.01$, one-way ANOVA followed by Holm-Sidak multiple comparison test. $\mathbf{p}$ Quantitative analysis of pTau in cortical neurons treated with or without $2.5 \mathrm{mM}$ metformin, $30 \mu \mathrm{M}$ phenformin and $30 \mu \mathrm{M}$ buformin. pTau was detected using the AT8 monoclonal antibody and normalized on total tau detected by Tau5 antibody. Data are expressed as percentage of Ctr. Bars represent the average percentage \pm SEM from 2 independent experiments. ${ }^{*} p<0.05,{ }^{* *} p<0.01$, one-way ANOVA followed by Holm-Sidak multiple comparison test

in metformin-treated P301S mice, with augmented levels of tau monomers (Fig. 5a-b), dimers (Fig. 5a, c) and AT100 immunoreactivity (Fig. 5a). We next analyzed cerebral tau inclusions by immunohistochemistry. Brain sections were immunostained with the conformationdependent anti-tau antibody MC1 [36] or anti-phosphotau AT8 antibody and counterstained with the Congo red analogue FSB. All FSB positive $\left(\mathrm{FSB}^{+}\right)$neurons were immunoreactive for $\mathrm{MC} 1$ antibody (Fig. $5 \mathrm{~d}$ ), but only some of them were labeled by AT8 (Fig. 5e). We next counted the $\mathrm{FSB}^{+}$cells in the prefrontal cortex and hippocampus of P301S mice, chronically treated with metformin or untreated. In 5-month old P301S mice, $\mathrm{FSB}^{+}$inclusions were more abundant in the prefrontal cortex $\left(62.2 \pm 7.7\right.$ inclusions $/ \mathrm{mm}^{2}$; Fig. 5f) than in the hippocampus ( $2.2 \pm 0.6$ inclusions / $\mathrm{mm}^{2}$; Fig. $\left.5 \mathrm{~g}\right)$. When P301S mice were treated with metformin, the number of $\mathrm{FSB}^{+}$ inclusions significantly increased by 2.5 - and 2.8 -fold in the prefrontal cortex (Fig. 5f) and hippocampus (Fig. 5g), respectively. Similar results were obtained using Gallyas silver staining (Fig. 5h-k). The number of Gallyas + cells was significantly increased in the prefrontal cortex (Fig. 5h, j) and hippocampus (Fig. 5k) of P301S mice treated with metformin. Therefore, despite reducing tau phosphorylation, chronic treatment with metformin significantly increases the formation of insoluble aggregates with $\beta$-sheet secondary structure in vivo.

We hypothesized that metformin could increase tau inclusions through direct effects on tau aggregation. To test this, we evaluated whether metformin promotes aggregation of recombinant P301S mutant human tau (tauP301S) in vitro using an established heparin-induced aggregation protocol and the thioflavin $\mathrm{T}$ assay. When incubated in vitro with heparin, recombinant tauP301S aggregated into fibrils, as detected by both thioflavin $\mathrm{T}$ assay and negative staining transmission electron microscopy (Fig. 5l-n). The aggregation process was timedependent and quickly reached maximal fluorescence values (Fig. 5l) due to abundant tau fibrils (Fig. 5l). We then performed the assay substituting heparin with metformin or incubating recombinant tauP301S with both heparin and metformin. With metformin alone, recombinant tauP301S aggregates in $\beta$-sheet-containing species in a time-dependent manner (Fig. 5l), reaching fluorescence values equal to half of those obtained with heparin after 14 days in vitro. When incubated with both metformin and heparin, there was an increased aggregation lag-time and fluorescence levels were intermediate between those found with metformin or heparin alone (Fig. 5h). At negative staining TEM, aggregates obtained with metformin alone had a different structure compared to those obtained with heparin after 7 days of incubation (Fig. 5m-n). With heparin, tau forms abundant filaments (Fig. 5m). In contrast in presence of metformin, we observed branched aggregates, formed by sub-spherical units, with a diameter of around $40 \mathrm{~nm}$, aligned in beaded chains (Fig. 5n). These structures resembled tau protofibrils, formed by aligned spherical nucleation units (SNUs), previously described as precursors of tau filaments [37].

We next investigated whether other members of the biguanide class of antidiabetic drugs with different chemical structure, i.e., phenformin and buformin, share the pro-aggregation effect of metformin. After 7 days of incubation, buformin, but not phenformin, promoted tau aggregation in vitro (Fig. 5o). There were fewer 
aggregates with buformin than with metformin (Fig. 50). These results indicate that both metformin and to some extent buformin act as pro-aggregants on recombinant tau in vitro.

Considering the possibility that metformin may interact directly with tau, we postulated that the paradoxical effect on tau phosphorylation could be an artifact due to an interaction masking the epitope. To test this hypothesis, we spiked cortical lysates from 5-month old P301S mice with increasing concentrations $(2.5-250 \mu \mathrm{M})$ of metformin and analyzed phospho-tau by western blot with the AT8 antibody. The amount of phospho-tau detected was similar in all samples, irrespective of metformin concentration (Ctr, $1 \pm 0.001 ; 2.5 \mu \mathrm{M}$ Met, $1.4 \pm 0.1$; $25 \mu \mathrm{M}$ Met, $0.8 \pm 0.07 ; 250 \mu \mathrm{M}$ Met, $1 \pm 0.1 ; P=0.06$, one-way ANOVA), indicating that potential tau interaction and epitope masking do not cause the effects of metformin on phosphorylation.

Finally, we investigated whether buformin and phenformin also affect tau phosphorylation. Due to toxicity, these biguanides could not be used at concentration equimolar with metformin and were applied to primary neurons at $30 \mu \mathrm{M}$. At this concentration, phenformin significantly reduced tau phosphorylation in primary cortical neurons, while buformin did not have any effect on tau phosphorylation levels (Fig. 5p).

In summary, metformin concurrently induces tau dephosphorylation and promotes its aggregation, while other biguanides retain only one or the other of these activities.

\section{Metformin treatment enhances hyperactive behavior in the open field test}

Since metformin treatment shows a dual action on tauopathy, by reducing tau phosphorylation and increasing formation of aggregates with $\beta$-sheet secondary structure, we investigated whether the drug's effects affected the behavioral performance in the open field (OF) task.

In the OF, P301S mice display a hyperactive behavior (i.e., increased distance travelled and speed) without changes of rearing behavior [20]. Consistently, we found that 5 month old P301S mice travel an increased distance, move at higher speed in the OF (Fig. 6a-b) than WT mice, but have preserved rearing behavior (Fig. 6c). The hyperactive behavior in the OF has been ascribed to abnormal activity of both the prefrontal cortex [38] and hippocampus [39], which in metformin-treated P301S mice, have an increased burden of inclusions. To investigate whether metformin treatment causes behavioral changes, P301S mice treated with or without metformin were subjected to the OF tasks at 4.5 months of age. At this age, despite extensive brain tauopathy, mice still eat and drink normally, and move freely. Chronic treatment with metformin significantly increased the hyperactive behavior of P301S mice. In metformintreated P301S mice, travelled distance and speed were significantly higher than those of untreated transgenic mice (Fig. 6d-e). The number of rearings was also significantly higher in metformin-treated than untreated P301S mice (Fig. 6f). When treated with metformin, 5 out of 9 P301S mice also showed abnormal jumping activity (number of jumps / $10 \mathrm{~min}, 3.3 \pm 1.36$ ), which was never observed in untreated P301S mice. The time spent in the center of the arena was similar in all treatment groups (Ctr, $0.1 \pm 0.04$; Met, $0.1 \pm 0.01$. $P=0.5$, Student $t$-test).

Overall, these data indicate that chronic treatment with metformin enhances the hyperactivity typical of P301S mice.

\section{Metformin treatment exacerbates hindlimb extension reflex deficit in P301S mice}

To examine the effects of metformin treatment on neurodegeneration, we evaluated hindlimb extension reflex, which is as an index of motor neuron degeneration [40], throughout the 4-month treatment period. In untreated P301S mice, leg extension progressively deteriorated with age until the final stage, when the hindlimbs were completely retracted with clasped and clenched paws (Fig. 6g). From 18 weeks of age, P301S mice treated with metformin scored significantly worse than untreated transgenic mice (Fig. 6g), indicating that metformin exacerbates hindlimb neurogenic paralysis.

\section{Metformin treatment induces activation of caspase 3 and cleavage of tau in primary cortical neurons and in the P301S mouse brain}

Caspase 3 cleaves tau protein at Asp 421 forming a cleaved-tau (c-Tau) fragment [41, 42], which facilitates tau filament formation in vitro [41, 42] and in vivo [43] and has detrimental effects on synaptic structures [44]. To investigate whether metformin affects caspase 3 mediated-tau cleavage and synapses, we treated primary cortical neurons with metformin for $24 \mathrm{~h}$ and examined active, cleaved caspase 3 , the levels of its cleavage products c-Tau and cleaved-PARP (c-PARP) and the post-synaptic protein PSD95. In cultured neurons, metformin treatment induces caspase 3 activation, increased levels of c-Tau and c-PARP (Fig. 6h-i) and reduces the expression of post-synaptic density 95 (PSD95; Fig. 6i). Through immunocytochemical analysis, we also found that metformin significantly reduced the number of clusters with overlapping immunoreactivity for the presynaptic synapsin I and post-synaptic PSD95 proteins (Fig. 6j), indicating an overall loss of synaptic boutons.

To investigate whether caspase-mediated cleavage of tau occurs in vivo, we analyzed both total and cleaved caspase 3 expression in P301S mice chronically treated 


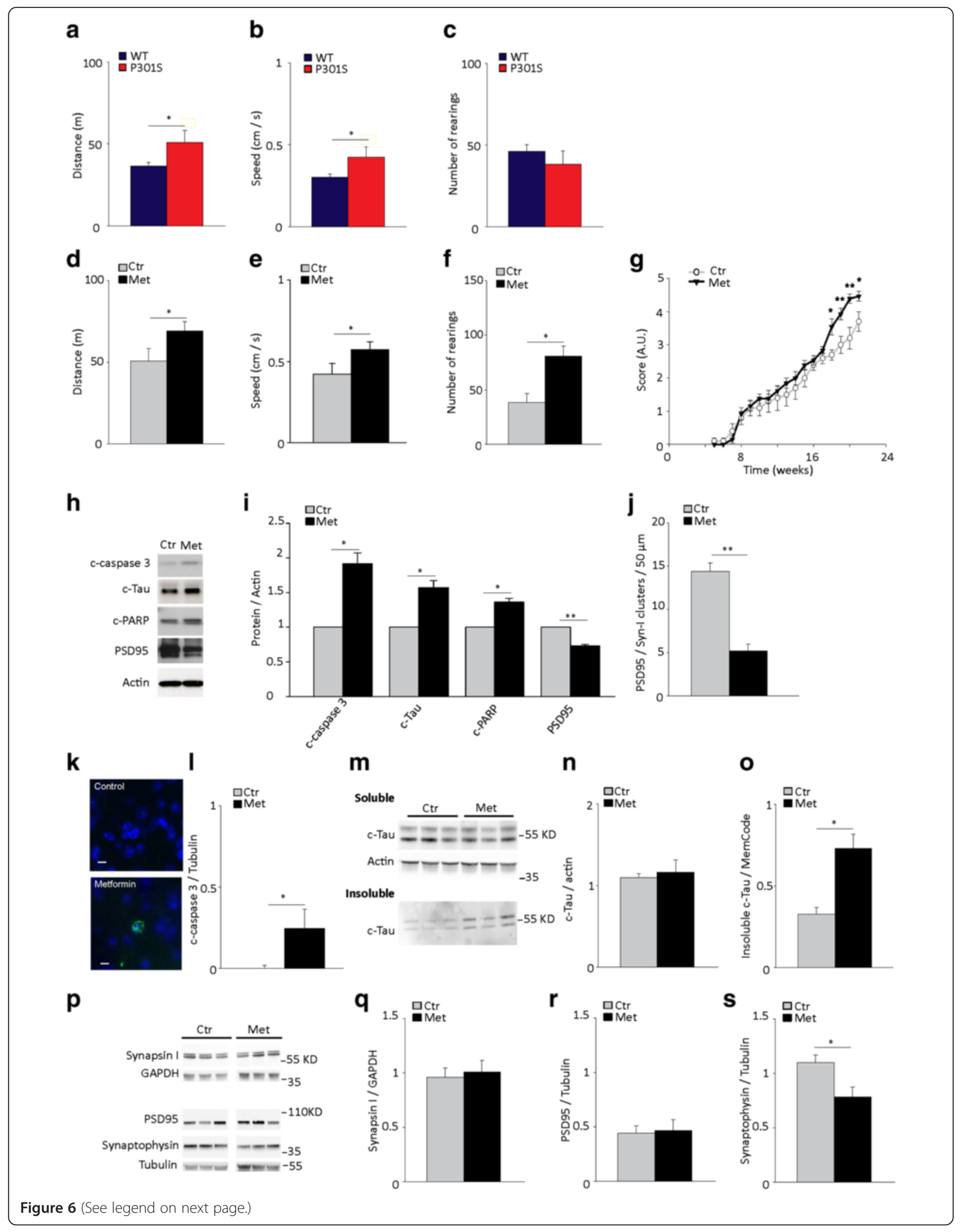




\begin{abstract}
(See figure on previous page.)
Figure 6 Metformin worsens hindlimb atrophy and hyperactive behavior and induces caspase 3 activation and tau cleavage. a-c Open field test in 5-month old P301S transgenic mice and age-matched WT non transgenic mice. Distance travelled (a), speed (b) and number of rearings (c) are shown. Bars represent the average values \pm SEM. ${ }^{*} p<0.05$, Student $t$-test. $n=9 /$ group. $\mathbf{d}-\mathbf{g}, \mathbf{k}-\mathbf{s}$. P301S mice were treated with or without metformin (Met) for 4 months starting from 1 month of age. $\mathbf{d}$-f. Open field test. Distance travelled (d), speed (e) and rearing (f) are shown. Bars represent the average values \pm SEM. ${ }^{*} p<0.05$, Student $t$-test. Panels $d$-f: Ctr, $n=11$; Met, $n=9$. $\mathbf{g}$ Hind limb extension test in P301S mice treated with or without metformin. Data points represent the average score \pm SEM. ${ }^{*} p<0.05$, two-way ANOVA followed by Holm-Sidak multiple comparison test. A.U., arbitrary units. Ctr, $n=12$; Met, $n=13$. $\mathbf{h}$-j. Primary cortical neurons were treated with or without $0.5 \mathrm{mM}$ metformin for 24 h. h-i. Western blot (h) and quantitative analyses (i) of cleaved caspase 3 (c-caspase 3), c-Tau, c-PARP and PSD95. Protein levels were normalized to actin. Bars represent the average values \pm SEM. ${ }^{*} p<0.05,{ }^{* *} p<0.01$, Student $t$-test. $n=3 /$ group. $\mathbf{j}$. Quantification of clusters with overlapping synapsin-I and PSD95 immunoreactivity. Bars represent the average \pm SEM. ${ }^{* *} p<0.01$, Student $t$-test. $n=11 /$ group. $\mathbf{k}$ Representative confocal maximal projection images of active c-caspase 3 immunoreactivity (green) in the prefrontal cortex of untreated and metformin-treated P301S mice. Nuclei are counterstained with Hoechst 33342. Scale bar $10 \mu \mathrm{m}$. I Quantitative analysis of active c-caspase 3. c-caspase 3 was analyzed by western blot and protein levels were normalized to tubulin. Bars represent the average \pm SEM. $n=7 /$ group. ${ }^{*} p<0.05$, Student $t$-test. $\mathbf{m}$ Western blot analysis of cleaved-tau (c-Tau) in the soluble and sarkosyl-insoluble fraction of metformin-treated and untreated P301S mouse cortex. n-o Quantitative analysis of cleaved Tau (c-Tau) in the soluble (n) and insoluble (o) cortical fraction. c-Tau was analyzed by western blot and protein levels were normalized to actin (n) or MemCode (o). Bars represent the average \pm SEM. Panel n: $n=7 /$ group. Panel o: $n=3 / g r o u p$. p Western blot analysis of synapsin I, PSD95, synaptophysin, tubulin and GAPDH in the cortex of P301S mice treated with or without metformin. q-s. Quantitative analysis of synapsin I (q), PSD95 (r) and synaptophysin (s). Protein levels were analyzed by western bot and normalized to tubulin or GAPDH. Bars represent the average \pm SEM. ${ }^{*} p<0.05$, Student $t$-test. Panel q: $n=7$ / group. Panel r: Ctr, $n=13 ;$ Met, $n=10$. Panel s: Ctr, $n=13 ;$ Met, $n=11$
\end{abstract}

with or without metformin. Caspase 3 total protein expression was similar across experimental groups (caspase/tubulin. P301S: Ctr, $0.2 \pm 0.06$; Met, $0.2 \pm 0.03$, $P=0.6$, Student t- test). Consistent with previous findings [18], in untreated P301S mice, cells immunoreactive for active cleaved caspase 3 were never observed in the cortex (Fig. 6k); levels of active cleaved caspase 3 were barely detectable by western blot. After chronic treatment with metformin, some cells were immunoreactive for active caspase 3 in the cortex of P301S mice (Fig. 6k) and cortical levels of active caspase 3 were significantly elevated (Fig. 6l). We next examined c-Tau in the soluble and sarkosyl-insoluble fractions of the cortex of metformin-treated P301S mice. Levels of soluble c-Tau were similar in metformin-treated and untreated P301S mice (Fig. 6m, n). However, in the sarkosyl insoluble fraction, c-Tau levels were significantly higher in metformin-treated P301S mice compared to untreated mice (Fig. 6m, o). To investigate whether chronic metformin affects synapses in vivo, we analyzed the expression of pre- (i.e., synaptophysin and synapsin I) and postsynaptic (i.e., PSD95) proteins by Western blot. Despite levels of synapsin I and PSD95 were unchanged, the expression of synaptophysin was significantly reduced in P301S mice treated with metformin (Fig. 6p-s). Overall, these data suggest that in P301S mice, chronic treatment with metformin induces a small but significant activation of caspase 3, increased caspase-cleaved tau in the tau filament-containing sarkosyl-insoluble cerebral fraction and affects the expression balance of pre-synaptic proteins.

\section{Discussion}

Our findings demonstrate that chronic administration of metformin acts on tau pathology with two distinct mechanisms. First, it reduces tau phosphorylation in the cortex and hippocampus, possibly by inducing PP2A expression via the AMPK/mTOR pathway. Second, it increases the amount of insoluble tau and the number of inclusions with $\beta$-sheet aggregates in the brain of P301S mice, likely promoting tau aggregation through direct interaction with the protein. Further, metformin exacerbates hindlimb atrophy, increases P301S hyperactive behavior and induces the activation of caspase 3 with concomitant c-Tau accumulation and synaptic changes.

In $\mathrm{AD}$ patients, brain insulin resistance also occurs independently of diabetes or peripheral insulin resistance [6] and is likely a consequence of $A \beta$ pathology $[6,45,46]$. Indeed, $A \beta$ oligomers downregulate insulin receptors in primary cortical neurons [46] and induce insulin resistance in cultured hippocampal neurons [45]. Although insulin resistance markers co-localize with tau inclusions in AD brain [7], the role of tau pathology in the onset of insulin resistance has been unclear: our findings indicate that the two are likely independent. In the P301S mouse, a model of cerebral tauopathy, we find neither peripheral nor central insulin resistance. Indeed, peripheral glucose homeostasis, and brain levels of glucose and insulin are comparable to WT mice and brain insulin signaling is unaffected.

Metformin acts as an insulin sensitizer and enhances glucose utilization in peripheral tissues independently from insulin signaling, via inhibition of mitochondrial complex I and AMPK activation (reviewed in ref. [47]). Metformin has hypoglycemic effects only in the context of diabetes, without affecting glycemia in non-diabetic subjects [48]. Accordingly, we find that chronic metformin affects neither glycemia nor brain insulin signaling 
in P301S mice, which do not have insulin resistance. Still, metformin has metabolic effects independent of glucose lowering, including induction of a gene expression profile typical of caloric restriction and effects on gut folate microbial metabolism, which have been associated with an increased lifespan in C. elegans $[49,50]$, rats [51] and one, but not another, strain of mice [52]. These findings served as basis to design and propose human studies investigating the potential use of metformin to promote healthy aging [53]. Also, in $\mathrm{db} / \mathrm{db}$ mice, metformin reduces the phosphorylation of endogenous murine tau without affecting the hyperglycemia induced by insulin resistance [14]. Similarly, in P301S mice, chronic metformin treatment reduces tau phosphorylation on several epitopes, without altering glycemic levels, suggesting a disconnection between the drug's hypoglycemic action and effects on tau.

Metformin actions on tau phosphorylation may occur via insulin-independent mechanisms, involving AMPK/ mTOR and PP2A. It has been previously shown that mTOR plays a key role in modulating tau phosphorylation in vitro and in vivo. Rapamycin reduces tau phosphorylation in primary rodent neurons [17] and in P301S mice $[54,55]$ and prevents the hyperphosphorylation of tau induced either by high glucose diet [56] or $A \beta$ [57] in the 3XTg-AD mouse. Our results indicate that mTOR inhibition through AMPK is required to activate PP2A and dephosphorylate tau and that this pathway functions independently of insulin.

Tau phosphorylation is also regulated by several kinases. GSK3 $\beta$ plays a key role in tau phosphorylation [24] and is inhibited upon activation of different pathways, including insulin signaling via AKT [58]. In the brain of metformin-treated P301S mice, AKT and insulin signaling are overall unaffected. Accordingly, despite a small trend toward an increase, inhibition of GSK3 $\beta$ is not significantly altered in the cortex of P301S mice treated with metformin, indicating that signaling through this kinase is not involved in the dephosphorylating action of metformin.

Surprisingly, despite reducing tau phosphorylation, chronic metformin increases both the cortical amount of insoluble tau and the number of cells containing inclusions with $\beta$-sheet conformation (positively stained by FSB and Gallyas) in the cortex and hippocampus of P301S mice. This is possibly due to different concurring mechanisms. First, our in vitro results indicate that metformin has pro-aggregation effects, leading to the formation of tau aggregates containing $\beta$-sheet secondary structure as revealed by thioflavin $\mathrm{T}$ binding. The thioflavin $\mathrm{T}$ signal of aggregates induced by metformin is lower than that of filaments obtained with heparin. This is possibly due to different ultrastructural features. In the presence of heparin, tau aggregates in long filaments, while metformin-induced aggregates appear as tau protofibrils made of globular oligomers. Consistently, Western blot analysis of sarkosyl-insoluble tau reveals that in the cortex of P301S mice treated with metformin there is an increased amount of oligomeric species, mainly dimers. Metformin-induced globular aggregates resemble SNUs, which form during the initial stages of heparin-induced aggregation in vitro and likely represent tau oligomers or precursors of tau filaments [37]. It has been shown that SNUs bear $\beta$ sheet secondary structure [59]. However, the $\beta$-sheet content is somehow lower than that of heparininduced aggregates and is associated with reduced thioflavin $\mathrm{T}$ signal [59]. Within this context, our results suggest that chronic exposure to metformin may catalyze the aggregation of tau by promoting the formation of oligomeric species or SNUs.

An alternate mechanism by which metformin may increase the amount of insoluble tau filamentous pathology in vivo is through caspase-mediated cleavage of tau. Caspase 3 cleaves tau at Asp421, forming a truncated form of tau, which aggregates readily and triggers the assembly of full-length tau into insoluble fragments [41]. Previous studies demonstrated that caspase 3mediated cleavage of tau is an early event in AD tau pathology [42]. Caspase 3 activation is induced by appoptosin overexpression, which is increased in the brain of patients with $\mathrm{AD}$ and frontotemporal dementia with tau inclusions [44]. In living $\mathrm{Tg} 4510$ tau transgenic mice, caspase 3 activation precedes and leads to tau inclusions formation [43]. Our findings indicate that in P301S tau transgenic mice, chronic metformin enhances this pathological process by inducing activation of caspase 3 and accumulation of c-Tau in the cerebral fraction containing insoluble tau filaments.

Among biguanides, only metformin displays a dual action on tauopathy, i.e. dephosphorylating and proaggregating. The butyl-substituted biguanide, buformin, retains some pro-aggregating properties, but has no significant effects on tau phosphorylation in vitro. Conversely, phenformin, which bears a phenyl-ethyl side chain, has no pro-aggregating property in vitro, but maintains tau dephosphorylating properties. It is unclear how metformin and buformin act on tau aggregation. Being positively charged at physiological $\mathrm{pH}$, it is plausible that these molecules electrostatically interact with tau, neutralizing negative charges and promoting aggregation. Further studies are warranted to clarify this fundamental point.

The potential benefits of metformin on cognition and $\mathrm{AD}$ are still controversial. In rodents, metformin significantly attenuated the cognitive impairment induced by insulin resistance and metabolic dysfunction as tested with the Morris water maze [12], but has 
no effect on other cognitive tasks, such as behavioral flexibility [13] or fear conditioning [14]. Still, metformin is neuroprotective in a mouse model of Huntington disease [60] and improves cognitive function in experimental models unrelated to metabolic dysfunction such as the pentylentetrazole-induced kindling [15] and the haloperidol-induced catalepsy in adult mice [16]. In contrast, other studies point to potential adverse effects of this drug on cognitive performance and $\mathrm{AD}$. For example, metformin has been associated with impaired cognitive performance in elderly patients (>75 years of age) with diabetes [61]. Further, diabetic patients taking metformin have an increased risk of developing $\mathrm{AD}$ than those taking other antidiabetic drugs [62]. Lastly, metformin increases the generation of $A \beta$ in cultured neurons due to induction of BACE expression [63]. These findings together with our observation that metformin may promote tau aggregation in vivo raise concerns on the potential overall benefits of metformin for $\mathrm{AD}$ and require further investigation in the elderly population.

Previous intervention studies with drugs targeting tau pathology report that a parallel decrease in both phosphorylation and aggregation of tau improves behavioral outcomes in the P301S mouse [54, 64]. Our results instead indicate that metformin's opposing actions on tau phosphorylation and aggregation worsens hindlimb atrophy and the hyperactive behavior of P301S mice. Such behavioral outcomes suggest that in $\mathrm{AD}$, metformin may negatively impact on agitation, which is one of the most disturbing neuropsychiatric symptoms of AD [65]. However, the behavioral phenotypes evaluated in our study are unrelated to cognitive changes associated with AD. Unfortunately, the strong motor impairment of the P301S transgenic mouse limits the possibility of investigating the effects of tauopathy on cognitive domains. Thus, further studies are warranted to fully clarify the role of tau aggregates and/or potential tau-unrelated actions of metformin on cognition in other transgenic models of tauopathy with cognitive deficits and normal motor function, such as the $\mathrm{Tg} 4510$ mouse [66].

\section{Conclusions}

Our findings indicate that metformin pro-aggregation effects mitigate the potential benefits arising from its dephosphorylating action. Metformin is the most widely prescribed antidiabetic drug, accounting for about $50 \%$ of prescriptions for non-insulin antidiabetic drugs in 2012 [67]. In the elderly population, there is a high degree of $\mathrm{AD}$ and $\mathrm{T} 2 \mathrm{DM}$ comorbidity due to the high incidence of these pathological conditions during aging $[68,69]$ and T2DM patients have an increased risk of developing $\mathrm{AD}[3,4]$. Due to its dual actions on tau phosphorylation and aggregation, in chronic administration regimens, metformin may unpredictably impact the development of tauopathy with undefined outcomes in elderly diabetic patients at risk for AD. Our results indicate that the effects of metformin on tau pathology manifest at doses yielding serum concentrations consistent with those of therapeutic dosing in humans [22]. Given the projected increase of prevalence of both diabetes and $\mathrm{AD}$ over the next decades [68, 69], further studies are warranted to investigate the effects of metformin on $\mathrm{AD}$ development, its contribution to the increased risk of $\mathrm{AD}$ associated with $\mathrm{T} 2 \mathrm{DM}$ and its therapeutic potential for tau-related neurodegenerative conditions. Conversely, from a long-term perspective, our findings indicate that the effects of metformin on tau phosphorylation and aggregation could be dissociated through chemical modifications and point to AMPK/mTOR signaling as a potential druggable target for tauopathy.

\section{Methods}

\section{Antibodies and reagents}

The following primary antibodies were used: mouse monoclonal antibodies against GSK3 $\beta$ (Millipore), IR $\beta$, S6 (Santa Cruz), $\beta$ I-tubulin (Sigma), $\beta$-actin (Sigma), caspase cleaved tau (Millipore), c-PARP, AKT (pan), IRS1 (Cell Signaling), PSD95 (Cell Signaling for Western blot or Millipore for immunocytochemistry), Synapsin-I (Millipore), GFP (Roche) and Rheb (Santa Cruz Biotechnologies); rabbit polyclonal antisera against $\mathrm{p}[$ Ser1162/1165]IR $\beta, \quad \mathrm{p}[$ S9]GSK3 $\beta$, AMPK, $\mathrm{p}$ [T172]AMPK, PP2A, p[S240/244]S6, mTOR, p[S2448]mTOR, p[S473]AKT, active cleaved caspase 3 (Cell Signaling), actin (Sigma) and p[S616]IRS1 (Invitrogen), Synaptophysin (Cell Signaling). For total tau and phospho-tau analysis, we used the monoclonal antibodies MC1 [36] and PHF1 [70] (kind gift of Dr P.Davies, Albert Einstein College of Medicine, New York, NY), AT100, AT270 (Autogen Bioclear), Tau5, AT8 (Calbiochem) and the polyclonal anti-p[S262]Tau antibody (Invitrogen). Secondary antibodies conjugated with Alexa fluorophores were from Invitrogen. For western blot analysis, horseradish-peroxidase (HRP)-conjugated secondary antibodies (Thermo Scientific) or ECL Plex Cy3conjugated goat anti-mouse IgG and $\mathrm{Cy} 5$-conjugated goat anti-rabbit IgG (GE Healthcare) were used.

Stock solutions of metformin, phenformin (Sigma), buformin (Santa Cruz) were prepared in water. Insulin (Humulin $\mathrm{R}^{\bullet} \mathrm{U}-500,100 \mathrm{UI} / \mathrm{ml}$, Eli Lilly), heparin (12$15 \mathrm{kDa}, 5000 \mathrm{UI} / \mathrm{ml}$, Sirton Pharmaceuticals), rapamycin (LC labs; $25 \mathrm{mM}$ in Ethanol), dorsomorphin (25 $\mathrm{mM}$ in DMSO), and okadaic acid (Sigma; $250 \mu \mathrm{M}$ in DMSO) were used for experiments in vitro. Unless otherwise 
specified, general reagents and chemicals were from Sigma and cell culture reagents were from Invitrogen.

\section{Animals and pharmacological treatments}

Male homozygous P301S transgenic [18] and agematched C57/Bl6 wild type (WT) non-transgenic mice were used. Animal health and comfort were veterinarycontrolled. Mice were housed in filtered cages in a temperature-controlled room with a 12:12 h dark/light cycle with ad libitum access to water and food. All animal experiments were performed in full compliance with the European Community Council directive dated 86/609/ EEC, the revised directive 2010/63/EU and were approved by the Italian Ministry of Health and by IIT Animal Facility Committee. At 4 weeks of age, P301S were randomly assigned to treatment or control groups (1215 mice/group). Animals in the treatment group received $2 \mathrm{mg} / \mathrm{ml}$ metformin in the drinking water for 4 months as previously described [60]. Drinking bottles were replenished with fresh water or metformin solution every week. The dose of metformin was equivalent to $\approx 300 \mathrm{mg} / \mathrm{kg} / \mathrm{day}$ and was selected based on pharmacokinetic studies of metformin distribution in rodents [71] and initial pharmacokinetic analyses in WT and P301S mice treated for 7 days with metformin. In rats, chronic administration of such dose achieves plasma levels $(7.6 \mu \mathrm{mol} / \mathrm{l})$ [71] comparable to those obtained by therapeutic dosing in humans $(7.8 \div 23.3 \mu \mathrm{mol} / \mathrm{l})[22]$ and yields similar levels in the frontal cortex $(4.3 \pm 1.0 \mathrm{nmol} / \mathrm{g}$ of tissue $)$ and hippocampus $(4.3 \pm 0.7 \mathrm{nmol} / \mathrm{g})$ [71]. Using HPLC-MS analysis as in [71], we measured the concentration of metformin in plasma and brain of WT and P301S mice treated for 7 days. Metformin concentration in plasma was in the low micromolar range and was similar in WT and P301S mice treated for 7 days (Additional file 1: Table S1). Levels of metformin in the brain were also comparable in WT and P301S mice (Additional file 1: Table S1). In untreated WT and P301S mice, metformin was undetectable in plasma and brain. Levels of metformin were also determined in the plasma of P301S mice treated for 4 months. After chronic treatment, plasma levels of metformin $(\mu \mathrm{mol} / 1 \pm \mathrm{SD}, \quad 0.7 \pm 0.4, n=6)$ were similar to those achieved by 7 day administration (Additional file 1 : Table S1). During chronic administration with metformin, body weight, glycemia, water and food consumption were monitored weekly. Glycemia, water and food consumption were unaffected by metformin (Additional file 1: Figure S4). In P301S mice, body weight steadily increased from 1 to 4 months of age. From 4 months of age, the body weight stops increasing (Additional file 1: Figure S4A), because of progressive muscle atrophy [18]. Metformin treatment did not significantly influence body weight.

\section{Intraperitoneal glucose tolerance test and insulin tolerance test}

For IPGTT, after fasting overnight for 16 h, 5-month old mice were challenged by intraperitoneal injection of $2 \mathrm{~g} / \mathrm{kg}$ glucose bolus. For ITT, mice were adapted by intraperitoneal saline solution injection for 3 days. After fasting for $6 \mathrm{~h}$, mice were injected intraperitoneally with $0.5 \mathrm{UI} / \mathrm{kg}$ insulin. Blood samples were drawn from tail nicks over a $2 \mathrm{~h}$ period at selected time intervals. Blood glucose content was measured by using GlucoCards and the GlucoCard G Meter (A.Menarini), following the manufacturer's instructions.

\section{Glucose and insulin assays}

Glucose was measured using the Amplex red glucose assay kit (Invitrogen) following the manufacturer's instructions. Mouse hemi-cortices were lysed in $20 \mathrm{mM}$ Tris $\mathrm{HCl} \mathrm{pH} \mathrm{7.5,} 150 \mathrm{mM} \mathrm{NaCl} 1 \mathrm{mM}$ EDTA, $1 \mathrm{mM}$ EGTA, 1 \% Triton X-100, and phosphatases and proteases inhibitors by trituration using a glass-glass dounce tissue homogenizer on ice. Lysates were spun at 30,000 x g using a Beckman Optima Ultra Centrifuge and the MLA 130 Rotor for $30 \mathrm{~min}$ at $4{ }^{\circ} \mathrm{C}$. The supernatant was collected for glucose measurement with Amplex red. The fluorescence values were read at $545 \mathrm{~nm}$ excitation and $590 \mathrm{~nm}$ emission wavelengths using a Victor 3 Multi-label Microplate Reader (Perkin Elmer).

Cortical insulin content was measured using a specific sandwich ELISA for mouse insulin (Millipore) following the manufacturer's instructions.

\section{Behavioral tests}

\section{Hind limb extension test}

The hind limb extension test [40] was performed weekly for the entire treatment period. Mice were held at the tip of the tail and suspended $30 \mathrm{~cm}$ above the floor for 20 s. Mice were scored from 0-5 based on the degree of hindlimb extension reflex or the presence of paw clasping. An animal received a score of 0 when the leg extension reflex was normal. Score 1 and 2 were assigned when mice retracted the hindlimbs after 15 or $5 \mathrm{~s}$, respectively. Score 3 and 4 were given when mice showed asymmetric retraction of one leg (score 3) or both legs (score 4) from the beginning of the test. Mice scored 5 when hindlimbs were completely retracted towards the body and paws were clasped for the entire test time.

\section{Open-field}

The open field protocol was adapted from [20]. Briefly, at 17-18 weeks of age, all mice underwent a single $20 \mathrm{~min}$ trial session of open-field testing. Mice were first acclimated to the room for $15 \mathrm{~min}$ the same day of testing. To start the test, each animal 
was placed facing the wall in an open-field arena $(44 \mathrm{~cm} \mathrm{~L} \times 44 \mathrm{~cm} \mathrm{~W} \times 44 \mathrm{~cm} \mathrm{H})$ made of black plexiglass, with a light grey bottom. Behavioral performance was recorded using a video tracking system (Any-Maze; Ugo Basile, Varese, Italy). Behavioral analyses were carried out on recorded movies using the AnyMaze software (Stoelting). The same observer, who was unaware of the animals' genotype, assigned all scores. The 20-min trial session was divided into four blocks (sessions) of 5 min each. During the 20-min session, the frequency of the following behavioral parameters was scored: traveled distance, speed, time in the center, and jumping (only frequency). During the central $10 \mathrm{~min}$ test phase $\left(2^{\text {nd }}-3^{\text {rd }} 5\right.$-min sessions), the following behavioral parameters were scored: wall rearing, standing on the hindlimbs and touching the walls of the apparatus with the forelimbs; rearing, standing on the hindlimbs in the open (away from the walls of the apparatus); grooming, licking and mouthing its own fur, sometimes with the help of the forepaws.

Primary neuronal cultures and pharmacological treatment Primary cortical neurons were isolated from the brain of WT embryos of either sex at E18 as previously described [72]. Embryonic cortices were collected in DMEM, and cells were dissociated by incubation with trypsin/EDTA at $37^{\circ} \mathrm{C}$. Cells were then diluted in neurobasal medium containing B27 supplement, Glutamax, penicillin/ streptomycin and plated at a density of $7.0 \times 10^{5}$ cells/ well on 6-well plates coated with $0.1 \mathrm{mg} / \mathrm{ml}$ poly-Llysine (PLL; Sigma). Neurons were cultured at $37^{\circ} \mathrm{C}$ in a humidified incubator with $5 \% \mathrm{CO}_{2}$. After 6 days, the medium was replaced with medium containing B27 without insulin. Twenty-four hours later, neurons were incubated with or without $2.5 \mathrm{mM}$ metformin, $30 \mu \mathrm{M}$ phenformin, $30 \mu \mathrm{M}$ buformin, $10 \mu \mathrm{M}$ rapamycin, $10 \mu \mathrm{M}$ dorsomorphin and/or $10 \mathrm{nM}$ okadaic acid for $6 \mathrm{~h}$. Alternatively, neurons were incubated with or without $0.5 \mathrm{mM}$ metformin for $24 \mathrm{~h}$ as indicated in selected experiments. In selected experiments, neurons were maintained in medium containing B27 with insulin for the entire treatment period. After pharmacological treatments, neuronal viability was assessed using the MTT assay as described elsewhere [72]. None of the pharmacological treatments altered the viability of neurons over $6 \mathrm{~h}$ (Additional file 1: Table S2).

\section{Cortical neurons transduction with lentiviral particles}

Lentiviral plasmids pHAGE-CMV-Rheb(S16H)-IRESeGFP-W [73] and pHAGE-CMV-IRES-eGFP-W [74] were obtained by Addgene and verified by DNA sequencing. Lentiviral particles were produced according to [75]. Neurons were plated at a density of $5 \times 10^{5}$ /well onto PLL-coated 6-well plates, incubated at $37{ }^{\circ} \mathrm{C}$ with $5 \% \mathrm{CO}_{2}$ for 4 days and then transduced with $10 \mathrm{MOI}$ of lentiviral particles for $24 \mathrm{~h}$. Six days after infection, the medium was replaced and after $24 \mathrm{~h}$ neurons were treated for $6 \mathrm{~h}$ with $2.5 \mathrm{mM}$ metformin.

\section{Western blots}

Brain tissues or primary cortical neurons were sonicated in $150 \mathrm{mM} \mathrm{NaCl}, 10 \mathrm{mM}$ Tris, $\mathrm{pH}$ 7.4, $1 \mathrm{mM}$ EGTA, $0.5 \%$ Triton X-100, and protease and phosphatase inhibitors and incubated for $30 \mathrm{~min}$ on ice. Samples were spun at 20,800 $\mathrm{x}$ g in an Eppendorf 5417R centrifuge for $45 \mathrm{~min}$. Supernatants were collected and protein concentration was determined using the $\mathrm{BCA}$ kit (Pierce).

Equal amount of proteins were separated by electrophoresis on $10 \%$ SDS-PAGE as previously described [76] and transferred overnight at $4{ }^{\circ} \mathrm{C}$ onto Protran 0.2 NC nitrocellulose membranes (Amersham). Membranes were blocked for $1 \mathrm{~h}$ at room temperature with $5 \%$ nonfat milk or bovine serum albumin (BSA) in blocking buffer containing $0.05 \%$ Tween-20 in phosphate buffered saline (PBS) $\mathrm{pH} 7.4$ and incubated overnight at $4{ }^{\circ} \mathrm{C}$ with primary antibodies. Membranes were rinsed in Tris buffered saline pH 7.4 with $0.05 \%$ Tween 20 (TBST) and incubated for $1 \mathrm{~h}$ at room temperature with secondary antibodies. Chemiluminescent signals were visualized using the SuperSignal West Pico Chemiluminescent Substrate (Thermo Scientific) and acquired using Image Quant LAS 4000 mini (GE Healthcare). Fluorescent signals were acquired using Typhoon Trio + and Typhoon Scanner Control v5.0 software (GE Healthcare). Densitometric analysis was performed using Image software [77]. Protein levels were normalized on $\beta I$-tubulin or actin. Phosphorylated proteins were normalized to the respective total protein. Data were expressed as percentage of WT untreated mice unless otherwise specified.

\section{RNA isolation and quantitative real time PCR (qRT-PCR)}

RNA was isolated using the Qiazol extraction protocol with 5 PRIME Phase lock Gel Tubes (Fisher Scientific) according to the manufacturer's protocol. RNA was quantified using an ND1000 Nanodrop spectrophotometer (NanoDrop Technologies, Inc). Reverse transcription of $1 \mu \mathrm{g}$ of RNA was performed using the RT2 First Strand Kit (Qiagen, Hilden, Germany) according to the manufacturer's instructions. qRT-PCR was performed using the QuantiFast SYBR Green PCR Kit (Qiagen) on a 7900HT Real-time System Instrument equipped with Sequence Detection Systems 2.3 Software (Applied Biosystem) as previously described [72]. Data were normalized to the expression of multiple housekeeping genes, including actin, GAPDH and HPRT1, as 
described [72], and Ct values were converted into foldexpression values relative to control using qBase ${ }^{\text {PLUS }}$ software (Biogazelle). Primers are listed in Additional file 1: Table S3.

\section{Immunocytochemistry}

Neurons were fixed in $4 \%$ paraformaldehyde (PFA), permeabilized, blocked in $5 \%$ BSA and then incubated overnight at $4{ }^{\circ} \mathrm{C}$ with anti-synapsin-I and PSD95 antibodies in BSA. Specimens were visualized under a Decon microscope (Axio Observer Z1, ZEISS).

\section{Immunohistochemistry and confocal microscopy}

Mice were deeply anesthetized with $20 \%$ urethane in saline and transcardially perfused with saline followed by $4 \%$ PFA in PBS. Brains were then dissected, post-fixed in $4 \%$ PFA for $24 \mathrm{~h}$ at $4{ }^{\circ} \mathrm{C}$ and cryopreserved in $30 \%$ sucrose in PBS for $24 \mathrm{~h} .30 \mu \mathrm{m}$ sections were cut using a Microm HM450 sliding microtome (BioOptica). Immunohistochemical detection of tau and phospho-tau was performed as described [76] using sagittal sections collected from -0.48 to $-1.32 \mathrm{~mm}$ from bregma. Insoluble aggregates with $\beta$-sheet conformation were detected by Gallyas silver staining or staining with the Congo red analogue FSB (DojinDo Laboratories) [78] as previously described [76]. Hoechst-33342 (Sigma) was used to stain nuclei. For cell counts, fluorescence images of entire sections were collected using an automated Olympus BX51 microscope, equipped with a MBF Optonic CX9000 camera, UPLFLN SEMIAPO FLUORITE 10X NA objective and MBF Neurolucida V11 software. An experienced researcher blind to the nature of the samples counted the numbers of AT8-, Gallyas- and FSB-positive cells. 3-5 slices were analyzed per animal. Cell counts were normalized to the area of the respective brain region.

Confocal optical sectioning was performed with $1 \mu \mathrm{m}$ step using an inverted Confocal Leica TCS SP5 AOBS TANDEM Leica Las AF equipped with an HCX PL APO 40X 1.25 NA oil objective.

\section{Tau purification and aggregation}

Recombinant tau was produced as described previously [79]. Briefly, the cDNA of the 441-amino acid isoform of human brain tau $(2 \mathrm{~N}, 4 \mathrm{R})$ was cloned in the pET-21 plasmid and expressed in Escherichia coli BL21 (DE3). Cultures were grown to mid-log phase and isopropyl-1thio- $\beta$-D-galactopyranoside was added to $400 \mu \mathrm{M}$. After $4 \mathrm{~h}$ shaking at $220 \mathrm{rpm}$ at $30{ }^{\circ} \mathrm{C}$, cells were pelleted, lysed in $50 \mathrm{mM}$ PIPES pH 6.8 by boiling for $5 \mathrm{~min}$, placed on ice, and $1 \mathrm{mM}$ DTT was added. The lysate was spun at $38,000 \times \mathrm{g}$ for $1 \mathrm{~h}$ at $4{ }^{\circ} \mathrm{C}$. The supernatant was collected, subjected to ion exchange chromatography using HITRAP CM FF (GE Healthcare), eluted in
$50 \mathrm{mM}$ PIPES $\mathrm{pH} 6.8$ and a gradient of $\mathrm{NaCl}$ (up to $0.5 \mathrm{M}$ ). Fractions were run on a $10 \%$ Tris-glycine gel and stained with Comassie to examine recombinant tau. Tau-containing fractions were pooled, chromatographed on a Superdex-75 size exclusion column (GE Healthcare) and eluted in $25 \mathrm{mM}$ Tris- $\mathrm{HCl}, \mathrm{pH}$ 7.4. The absorbance at 220 and $280 \mathrm{~nm}$ was measured to determine the concentration of the freshly purified protein. Purified recombinant protein stocks were stored in aliquots at $-80^{\circ} \mathrm{C}$ until use.

Purified recombinant tau $(50 \mu \mathrm{M}), 37.5 \mu \mathrm{M}$ heparin (molar ratio tau/heparin $=0.75)$ and/or $30 \mu \mathrm{M}$ metfor min, buformin or phenformin were incubated at $37{ }^{\circ} \mathrm{C}$ for 8-15 days in PBS pH 7.4, containing $1 \mathrm{mM}$ EDTA and $1 \mathrm{mM}$ EGTA. Tau aggregation was monitored using the Thioflavin T (ThT; Sigma) assay. Sample fluorescence was examined using a Tecan Infinite plate reader set at $430 \mathrm{~nm}$ for excitation and $485 \mathrm{~nm}$ for emission. Tau aggregates were also analyzed by western blot and transmission electron microscopy.

\section{Sarkosyl extraction}

Sarkosyl-insoluble tau was extracted as described previously [76]. Briefly, tissues were homogenized in 10 volumes of cold extraction buffer $(10 \mathrm{mM}$ Tris- $\mathrm{HCl}$, $\mathrm{pH}$ 7.4, $0.8 \mathrm{M} \mathrm{NaCl}, 1 \mathrm{mM}$ EGTA, $10 \%$ sucrose) and the homogenates were spun for $30 \mathrm{~min}$ at $20,000 \times g$. After adding $1 \%$ sarkosyl, the samples were shaken for $1 \mathrm{~h}$ at room temperature and spun at 100,000 $\times g$ for $1 \mathrm{~h}$ at $4{ }^{\circ} \mathrm{C}$. The pellets containing insoluble tau were resuspended in $50 \mathrm{mM}$ Tris- $\mathrm{HCl}, \mathrm{pH} 7.4$ and stored at $4{ }^{\circ} \mathrm{C}$ until analysis by western blot.

\section{Negative staining transmission electron microscopy}

Recombinant tau protein aggregates were placed onto 300-mesh glow discharged carbon-coated grids and negatively stained in $2 \%$ uranyl acetate. The samples were observed with a FEI Tecnai F20 field emission gun transmission electron microscope (FEI Company, The Netherlands), working at an acceleration voltage of $80 \mathrm{keV}$ and equipped with a $2 \mathrm{k} \mathrm{X} 2 \mathrm{~K}$ Gatan Ultrascan CCD camera (Gatan company, USA).

\section{Statistical analysis}

Statistical analysis of groups with normal distributions was performed using the Student's $t$-test for two groups or ANOVA for multiple comparisons. One-way ANOVA or two-way ANOVA followed by multiple comparisons with the Holm-Sidak method was performed for more than two groups. Differences among groups were considered statistically significant when $\mathrm{p}<0.05$. Data throughout the text are reported as average values \pm SEM unless otherwise specified. 


\section{Additional file}

Additional file 1: Figure S1. Expression levels of key molecules in the insulin pathway in WT and P301S mouse cortex. Figure S2. Expression levels of key molecules in the insulin pathway in the cortex of P301S mouse treated with or without metformin. Figure S3. Expression levels of AMPK, S6, pS6, and tau in primary cortical neurons treated with or without metformin and/or specific blockers. Figure S4. Body weight, glycemia, water and food consumption in P301S mice treated with or without metformin. Table S1. Concentration of metformin in the plasma and brain of WT and P301S mice after treatment for 7 days. Table S2. Neuronal viability after pharmacological treatment for 6 h. Table S3. Primers used for qRT-PCR. (PDF $5110 \mathrm{~kb}$ )

\section{Abbreviations}

AD: Alzheimer disease; AKT: protein kinase B; AMPK: AMP-activated protein kinase; AUC: area under the curve; $A \beta$ : $\beta$-amyloid; BSA: bovine serum albumin; Buf: buformin; c-caspase 3: cleaved caspase 3; cDNA: coding DNA; c-PARP: cleaved PARP; CSF: cerebrospinal fluid; c-Tau: cleaved tau; Ctr: control; Dorso: dorsomorphin; GSK3 $\beta$ : glycogen synthase $3 \beta$; Hep: heparin; IPGT: intraperitoneal glucose tolerance test; IR: insulin receptor; IRS-1: IR scaffold-1; IRß: IR $\beta$ subunit; IT: insulin tolerance test; Met: metformin; mTOR: mammalian target of rapamycyn; OA: okadaic acid; OF: open field; P301S: P301S mutant human tau transgenic mouse; pAKT: phospho-AKT; pAMPK: phospho-AMPK; PBS: phosphate buffered saline; PFA: paraformaldehyde; PGSK3 3 : phospho-GSK3ß; Phe: phenformin; PP2A: protein phosphatase 2A; PSD95: post-synaptic density 95; pTau: phospho-tau; qRT-PCR: quantitative real time polymerase chain reaction; Rapa: rapamycin; SNUs: spherical nucleation units; T2DM: type 2 diabetes mellitus; TEM: transmission electron microscopy; ThT: thioflavin $T_{\text {; }}$ WT: wild type.

\section{Competing interests}

The authors declare that they have no competing interest.

\section{Authors' contributions}

EB, OA, FA, YZ performed pharmacological treatments, molecular and immunofluorescence analyses; EB, OA, YZ performed data analyses of metabolic, biochemical and molecular studies; TC, RM performed electron microscopy; VT gave support for tests, data analyses and interpretation of behavioral studies; LG and HX designed, supervised and coordinated all experiments and data analyses; EB, LG, YZ, HX wrote the manuscript; all authors critically discussed results, revised and approved the manuscript.

\section{Acknowledgements}

The authors thank Dr. M. Goedert, MRC Laboratory of Molecular Biology (Cambridge, UK) for kindly providing P301S mice and Dr. P. Davies, Albert Einstein College of Medicine (New York, NY, USA) for the gift of PHF-1 and MC1 antibodies. We are grateful to Drs Sabina Capellari and Sabrina Boninsegna at University of Bologna for advices and technical support with the Gallyas silver staining. This work was supported by intramural funds from Istituto Italiano di Tecnologia to L.G. and in part by grants from National Institute of Health (R01AG021173, R01AG038710, R01AG044420, and R01NS046673 to H.X.), Alzheimer's Association (H.X.), The Tanz Family Funds to H.X., and National Natural Science Foundation of China (91332114 and U1405222 to H.X.).

\section{Author details \\ ${ }^{1}$ Department of Neuroscience and Brain Technologies, Istituto Italiano di Tecnologia, Via Morego 30, Genoa, Italy. ${ }^{2}$ Fujian Provincial Key Laboratory of Neurodegenerative Disease and Aging Research, Institute of Neuroscience, College of Medicine, Xiamen University, Xiamen, Fujian 361102, China. ${ }^{3}$ Degenerative Diseases Program, Sanford Burnham Prebys Medical Discovery Institute, La Jolla, CA 92037, USA. ${ }^{4}$ Nanochemistry Department, Electron Microscopy Lab, Istituto Italiano di Tecnologia, Via Morego 30, Genoa, Italy. ${ }^{5}$ Present Address: AbbVie Deutschland GmbH \&Co. KG, Knollstr., 67061 Ludwigshafen, Germany.}

Received: 3 November 2015 Accepted: 1 February 2016 Published online: 09 February 2016

\section{References}

1. Bateman RJ, Xiong C, Benzinger TL, Fagan AM, Goate A, Fox NC, et al. Clinical and biomarker changes in dominantly inherited Alzheimer's disease. N Engl J Med. 2012:367:795-804.

2. Arriagada PV, Growdon JH, Hedley-Whyte ET, Hyman BT. Neurofibrillary tangles but not senile plaques parallel duration and severity of Alzheimer's disease. Neurology. 1992;42:631-9.

3. Gasparini L, Netzer WJ, Greengard P, Xu H. Does insulin dysfunction play a role in Alzheimer's disease? Trends Pharmacol Sci. 2002;23:288-93.

4. El Khoury NB, Gratuze M, Papon MA, Bretteville A, Planel E. Insulin dysfunction and Tau pathology. Front Cell Neurosci. 2014;8:22.

5. Cohen AD, Klunk WE. Early detection of Alzheimer's disease using PiB and FDG PET. Neurobiol Dis. 2014;72 Pt A:117-22.

6. Talbot K, Wang HY, Kazi H, Han LY, Bakshi KP, Stucky A, et al. Demonstrated brain insulin resistance in Alzheimer's disease patients is associated with IGF-1 resistance, IRS-1 dysregulation, and cognitive decline. J Clin Invest. 2012:122:1316-38.

7. Yarchoan M, Toledo JB, Lee EB, Arvanitakis Z, Kazi H, Han LY, et al. Abnormal serine phosphorylation of insulin receptor substrate 1 is associated with tau pathology in Alzheimer's disease and tauopathies. Acta Neuropathol. 2014;128:679-89.

8. Lesort M, Jope RS, Johnson GV. Insulin transiently increases tau phosphorylation: involvement of glycogen synthase kinase-3beta and Fyn tyrosine kinase. J Neurochem. 1999;72:576-84.

9. Hong $M$, Lee VM. Insulin and insulin-like growth factor-1 regulate tau phosphorylation in cultured human neurons. J Biol Chem. 1997;272:19547-53

10. Gupta A, Bisht B, Dey CS. Peripheral insulin-sensitizer drug metformin ameliorates neuronal insulin resistance and Alzheimer's-like changes. Neuropharmacology. 2011;60:910-20.

11. Yarchoan M, Arnold SE. Repurposing diabetes drugs for brain insulin resistance in Alzheimer disease. Diabetes. 2014:63:2253-61.

12. Pintana H, Apaijai N, Pratchayasakul W, Chattipakorn N, Chattipakorn SC Effects of metformin on learning and memory behaviors and brain mitochondrial functions in high fat diet induced insulin resistant rats. Life Sci. 2012:91:409-14.

13. McNeilly AD, Williamson R, Balfour DJ, Stewart CA, Sutherland C. A high-fatdiet-induced cognitive deficit in rats that is not prevented by improving insulin sensitivity with metformin. Diabetologia. 2012;55:3061-70.

14. Li J, Deng J, Sheng W, Zuo Z. Metformin attenuates Alzheimer's disease-like neuropathology in obese, leptin-resistant mice. Pharmacol Biochem Behav. 2012;101:564-74.

15. Zhao RR, Xu XC, Xu F, Zhang WL, Zhang WL, Liu LM, et al. Metformin protects against seizures, learning and memory impairments and oxidative damage induced by pentylenetetrazole-induced kindling in mice. Biochem Biophys Res Commun. 2014:448:414-7.

16. Adeyemi OO, Ishola IO, Adedeji HA. Novel action of metformin in the prevention of haloperidol-induced catalepsy in mice: Potential in the treatment of Parkinson's disease? Prog Neuropsychopharmacol Biol Psychiatry 2013. doi: 10.1016/j.pnpbp.2013.10.014. [Epub ahead of print].

17. Kickstein E, Krauss S, Thornhill P, Rutschow D, Zeller R, Sharkey J, et al. Biguanide metformin acts on tau phosphorylation via mTOR/protein phosphatase 2A (PP2A) signaling. Proc Natl Acad Sci U S A. 2010;107:21830-5.

18. Allen B, Ingram E, Takao M, Smith MJ, Jakes R, Virdee K, et al. Abundant tau filaments and nonapoptotic neurodegeneration in transgenic mice expressing human P301S tau protein. J Neurosci. 2002;22:9340-51.

19. Hampton DW, Webber DJ, Bilican B, Goedert M, Spillantini MG, Chandran S. Cell-mediated neuroprotection in a mouse model of human tauopathy. Jeurosci. 2010;30:9973-83.

20. Scattoni ML, Gasparini L, Alleva E, Goedert M, Calamandrei G, Spillantini MG. Early behavioural markers of disease in P301S tau transgenic mice. Behav Brain Res. 2010:208:250-7.

21. Delobel P, Lavenir I, Fraser G, Ingram E, Holzer M, Ghetti B, et al. Analysis of tau phosphorylation and truncation in a mouse model of human tauopathy. Am J Pathol. 2008;172:123-31.

22. Tucker GT, Casey C, Phillips PJ, Connor H, Ward JD, Woods HF. Metformin kinetics in healthy subjects and in patients with diabetes mellitus. $\mathrm{Br} \mathrm{J}$ Clin Pharmacol. 1981;12:235-46.

23. Liu F, Grundke-lqbal I, Iqbal K, Gong CX. Contributions of protein phosphatases PP1, PP2A, PP2B and PP5 to the regulation of tau phosphorylation. Eur J Neurosci. 2005;22:1942-50. 
24. Avila J, Leon-Espinosa G, Garcia E, Garcia-Escudero V, Hernandez F, Defelipe J. Tau phosphorylation by GSK3 in different conditions. Int J Alzheimers Dis. 2012;2012:578373.

25. Doble BW, Woodgett JR. GSK-3: tricks of the trade for a multi-tasking kinase. J Cell Sci. 2003;116:1175-86.

26. Rodgers JT, Vogel RO, Puigserver P. Clk2 and B56beta mediate insulinregulated assembly of the PP2A phosphatase holoenzyme complex on Akt. Mol Cell. 2011;41:471-9.

27. Hartley D, Cooper GM. Role of mTOR in the degradation of IRS-1: regulation of PP2A activity. J Cell Biochem. 2002;85:304-14.

28. Zhang HH, Lipovsky Al, Dibble CC, Sahin M, Manning BD. S6K1 regulates GSK3 under conditions of mTOR-dependent feedback inhibition of Akt. Mol Cell. 2006;24:185-97.

29. Magnuson B, Ekim B, Fingar DC. Regulation and function of ribosomal protein S6 kinase (S6K) within mTOR signalling networks. Biochem J. 2012;441:1-21.

30. Edinger AL, Thompson CB. Akt maintains cell size and survival by increasing mTOR-dependent nutrient uptake. Mol Biol Cell. 2002;13:2276-88.

31. Cheng SW, Fryer LG, Carling D, Shepherd PR. Thr2446 is a novel mammalian target of rapamycin (mTOR) phosphorylation site regulated by nutrient status. J Biol Chem. 2004;279:15719-22.

32. Hawley SA, Gadalla AE, Olsen GS, Hardie DG. The antidiabetic drug metformin activates the AMP-activated protein kinase cascade via an adenine nucleotide-independent mechanism. Diabetes. 2002;51:2420-5.

33. Zhou G, Myers R, Li Y, Chen Y, Shen X, Fenyk-Melody J, et al. Role of AMPactivated protein kinase in mechanism of metformin action. J Clin Invest. 2001;108:1167-74.

34. Yan L, Findlay GM, Jones R, Procter J, Cao Y, Lamb RF. Hyperactivation of mammalian target of rapamycin (mTOR) signaling by a gain-of-function mutant of the Rheb GTPase. J Biol Chem. 2006:281:19793-7.

35. Augustinack JC, Schneider A, Mandelkow EM, Hyman BT. Specific tau phosphorylation sites correlate with severity of neuronal cytopathology in Alzheimer's disease. Acta Neuropathol. 2002;103:26-35.

36. Dickson DW, Crystal HA, Bevona C, Honer W, Vincent I, Davies P. Correlations of synaptic and pathological markers with cognition of the elderly. Neurobiol Aging. 1995;16:285-98. discussion 298-304.

37. Xu S, Brunden KR, Trojanowski JQ, Lee VM. Characterization of tau fibrillization in vitro. Alzheimers Dement. 2010;6:110-7.

38. Pezze M, McGarrity S, Mason R, Fone KC, Bast T. Too little and too much: hypoactivation and disinhibition of medial prefrontal cortex cause attentional deficits. J Neurosci. 2014;34:7931-46.

39. Bardgett ME, Baum KT, O'Connell SM, Lee NM, Hon JC. Effects of risperidone on locomotor activity and spatial memory in rats with hippocampal damage. Neuropharmacology. 2006;51:1156-62.

40. Barneoud P, Lolivier J, Sanger DJ, Scatton B, Moser P. Quantitative motor assessment in FALS mice: a longitudinal study. Neuroreport. 1997:8:2861-5.

41. Gamblin TC, Chen F, Zambrano A, Abraha A, Lagalwar S, Guillozet AL, et al. Caspase cleavage of tau: linking amyloid and neurofibrillary tangles in Alzheimer's disease. Proc Natl Acad Sci U S A. 2003;100:10032-7.

42. Rissman RA, Poon WW, Blurton-Jones M, Oddo S, Torp R, Vitek MP, et al. Caspase-cleavage of tau is an early event in Alzheimer disease tangle pathology. J Clin Invest. 2004;114:121-30.

43. de Calignon A, Fox LM, Pitstick R, Carlson GA, Bacskai BJ, Spires-Jones TL, et al. Caspase activation precedes and leads to tangles. Nature. 2010:464:1201-4.

44. Zhao Y, Tseng IC, Heyser CJ, Rockenstein E, Mante M, Adame A, et al. Appoptosin-mediated caspase cleavage of tau contributes to progressive supranuclear palsy pathogenesis. Neuron. 2015;87:963-75.

45. Bomfim TR, Forny-Germano L, Sathler LB, Brito-Moreira J, Houzel JC, Decker $\mathrm{H}$, et al. An anti-diabetes agent protects the mouse brain from defective insulin signaling caused by Alzheimer's disease- associated Abeta oligomers. J Clin Invest. 2012;122:1339-53.

46. Zhao WQ, De Felice FG, Fernandez S, Chen H, Lambert MP, Quon MJ, et al. Amyloid beta oligomers induce impairment of neuronal insulin receptors. FASEB J. 2008;22:246-60

47. Viollet B, Guigas B, Sanz Garcia N, Leclerc J, Foretz M, Andreelli F. Cellular and molecular mechanisms of metformin: an overview. Clin Sci. 2012;122:253-70.

48. Hundal RS, Krssak M, Dufour S, Laurent D, Lebon V, Chandramouli V, et al. Mechanism by which metformin reduces glucose production in type 2 diabetes. Diabetes. 2000;49:2063-9.
49. Cabreiro F, Au C, Leung KY, Vergara-Irigaray N, Cocheme HM, Noori T, et al. Metformin retards aging in C. elegans by altering microbial folate and methionine metabolism. Cell. 2013;153:228-39.

50. De Haes W, Frooninckx L, Van Assche R, Smolders A, Depuydt G, Billen J, et al. Metformin promotes lifespan through mitohormesis via the peroxiredoxin PRDX-2. Proc Natl Acad Sci U S A. 2014;111:E2501-9.

51. Anisimov VN, Berstein LM, Egormin PA, Piskunova TS, Popovich IG, Zabezhinski MA, et al. Metformin slows down aging and extends life span of female SHR mice. Cell Cycle. 2008;7:2769-73.

52. Martin-Montalvo A, Mercken EM, Mitchell SJ, Palacios HH, Mote PL, Scheibye-Knudsen $\mathrm{M}$, et al. Metformin improves healthspan and lifespan in mice. Nat Commun. 2013;4:2192.

53. Hayden EC. Anti-Ageing pill pushed as bona fide drug. Nature. 2015;522:265-6

54. Ozcelik S, Fraser G, Castets P, Schaeffer V, Skachokova Z, Breu K, et al. Rapamycin attenuates the progression of tau pathology in P301S tau transgenic mice. PLoS ONE. 2013;8:e62459.

55. Caccamo A, Magri A, Medina DX, Wisely EV, Lopez-Aranda MF, Silva AJ, et al. mTOR regulates tau phosphorylation and degradation: implications for Alzheimer's disease and other tauopathies. Aging Cell. 2013;12:370-80.

56. Orr ME, Salinas A, Buffenstein R, Oddo S. Mammalian target of rapamycin hyperactivity mediates the detrimental effects of a high sucrose diet on Alzheimer's disease pathology. Neurobiol Aging. 2014;35:1233-42.

57. Caccamo A, Majumder S, Richardson A, Strong R, Oddo S. Molecular interplay between mammalian target of rapamycin (mTOR), amyloid-beta, and Tau: effects on cognitive impairments. J Biol Chem. 2010;285:13107-20.

58. van Weeren $P C$, de Bruyn KM, de Vries-Smits AM, van Lint J, Burgering BM. Essential role for protein kinase B (PKB) in insulin-induced glycogen synthase kinase 3 inactivation. Characterization of dominant-negative mutant of PKB. J Biol Chem. 1998:273:13150-6.

59. Maeda S, Sahara N, Saito Y, Murayama M, Yoshiike Y, Kim H, et al. Granular tau oligomers as intermediates of tau filaments. Biochemistry. 2007;46:3856-61.

60. Ma TC, Buescher JL, Oatis B, Funk JA, Nash AJ, Carrier RL, et al. Metformin therapy in a transgenic mouse model of Huntington's disease. Neurosci Lett. 2007:411:98-103.

61. Moore EM, Mander AG, Ames D, Kotowicz MA, Carne RP, Brodaty H, et al. Increased risk of cognitive impairment in patients with diabetes is associated with metformin. Diabetes Care. 2013;36:2981-7.

62. Imfeld P, Bodmer M, Jick SS, Meier CR. Metformin, other antidiabetic drugs, and risk of Alzheimer's disease: a population-based case-control study. J Am Geriatr Soc. 2012;60:916-21.

63. Chen Y, Zhou K, Wang R, Liu Y, Kwak YD, Ma T, et al. Antidiabetic drug metformin (GlucophageR) increases biogenesis of Alzheimer's amyloid peptides via up-regulating BACE1 transcription. Proc Natl Acad Sci U S A. 2009;106:3907-12.

64. Chai X, Wu S, Murray TK, Kinley R, Cella CV, Sims H, et al. Passive immunization with anti-Tau antibodies in two transgenic models: reduction of Tau pathology and delay of disease progression. J Biol Chem. 2011;286:34457-67.

65. Geda YE, Schneider LS, Gitlin LN, Miller DS, Smith GS, Bell J, et al. Neuropsychiatric symptoms in Alzheimer's disease: past progress and anticipation of the future. Alzheimers Dement. 2013;9:602-8.

66. SantaCruz K, Lewis J, Spires T, Paulson J, Kotilinek L, Ingelsson M, et al. Tau suppression in a neurodegenerative mouse model improves memory function. Science. 2005;309:476-81

67. Hampp C, Borders-Hemphill V, Moeny DG, Wysowski DK. Use of antidiabetic drugs in the U.S., 2003-2012. Diabetes Care. 2014;37:1367-74.

68. Hebert LE, Weuve J, Scherr PA, Evans DA. Alzheimer disease in the United States (2010-2050) estimated using the 2010 census. Neurology. 2013;80:1778-83.

69. Wild S, Roglic G, Green A, Sicree R, King H. Global prevalence of diabetes: estimates for the year 2000 and projections for 2030. Diabetes Care. 2004;27:1047-53.

70. Otvos Jr L, Feiner L, Lang E, Szendrei Gl, Goedert M, Lee VM. Monoclonal antibody PHF-1 recognizes tau protein phosphorylated at serine residues 396 and 404. J Neurosci Res. 1994;39:669-73.

71. Labuzek K, Suchy D, Gabryel B, Bielecka A, Liber S, Okopien B. Quantification of metformin by the HPLC method in brain regions, cerebrospinal fluid and plasma of rats treated with lipopolysaccharide. Pharmacol Rep. 2010;62:956-65. 
72. Ferrera D, Mazzaro N, Canale C, Gasparini L. Resting microglia react to A beta 42 fibrils but do not detect oligomers or oligomer-induced neuronal damage. Neurobiol Aging. 2014;35:2444-57.

73. Nie D, Di Nardo A, Han JM, Baharanyi H, Kramvis I, Huynh T, et al. Tsc2-Rheb signaling regulates EphA-mediated axon guidance. Nat Neurosci. 2010;13:163-72.

74. Mostoslavsky G, Kotton DN, Fabian AJ, Gray JT, Lee JS, Mulligan RC. Efficiency of transduction of highly purified murine hematopoietic stem cells by lentiviral and oncoretroviral vectors under conditions of minimal in vitro manipulation. Mol Ther. 2005;11:932-40.

75. Naldini L, Blomer U, Gallay P, Ory D, Mulligan R, Gage FH, et al. In vivo gene delivery and stable transduction of nondividing cells by a lentiviral vector. Science. 1996:272:263-7.

76. Gasparini L, Crowther RA, Martin KR, Berg N, Coleman M, Goedert M, et al. Tau inclusions in retinal ganglion cells of human P301S tau transgenic mice: Effects on axonal viability. Neurobiol Aging. 2011;32:419-33.

77. Schneider CA, Rasband WS, Eliceiri KW. NIH Image to ImageJ: 25 years of image analysis. Nat Methods. 2012;9:671-5.

78. Sato K, Higuchi M, Iwata N, Saido TC, Sasamoto K. Fluoro-substituted and 13C-labeled styrylbenzene derivatives for detecting brain amyloid plaques. Eur J Med Chem. 2004;39:573-8.

79. Hasegawa M, Smith MJ, Goedert M. Tau proteins with FTDP-17 mutations have a reduced ability to promote microtubule assembly. FEBS Lett. 1998:437:207-10.

\section{Submit your next manuscript to BioMed Central} and we will help you at every step:

- We accept pre-submission inquiries

- Our selector tool helps you to find the most relevant journal

- We provide round the clock customer support

- Convenient online submission

- Thorough peer review

- Inclusion in PubMed and all major indexing services

- Maximum visibility for your research

Submit your manuscript at www.biomedcentral.com/submit 